José Antonio Sumay Rey

\section{Hilberseimer: de la Hochhausstadt a la New City

\author{
Cambio social, vivienda y metrópoli
}

Palabras clave: Ludwig Hilberseimer, urbanismo moderno, racionalismo, vivienda moderna.

En torno a 1930 Ludwig Karl Hilberseimer abre una significativa etapa de revisión de sus primeros modelos urbanos, la Wohnstadt (Ciudad residencial, 1923) y la Hochhausstadt (Metrópoli vertical, 1924), buscando la adaptación a los intensos cambios sociales y politicos que la sociedad europea sufre en ese tiempo y cuyo resultado final es un nuevo modelo, más descentralizado e integrado con el territorio, la New City (c. 1932). En este trabajo se han revisado sus investigaciones durante ese periodo, descubriendo así una precisa metodología proyectual, basada en la abstracción y en la descomposición elemental que realiza un detallado tránsito por los diversos niveles del proyecto moderno: desde la estancia a la metrópoli.

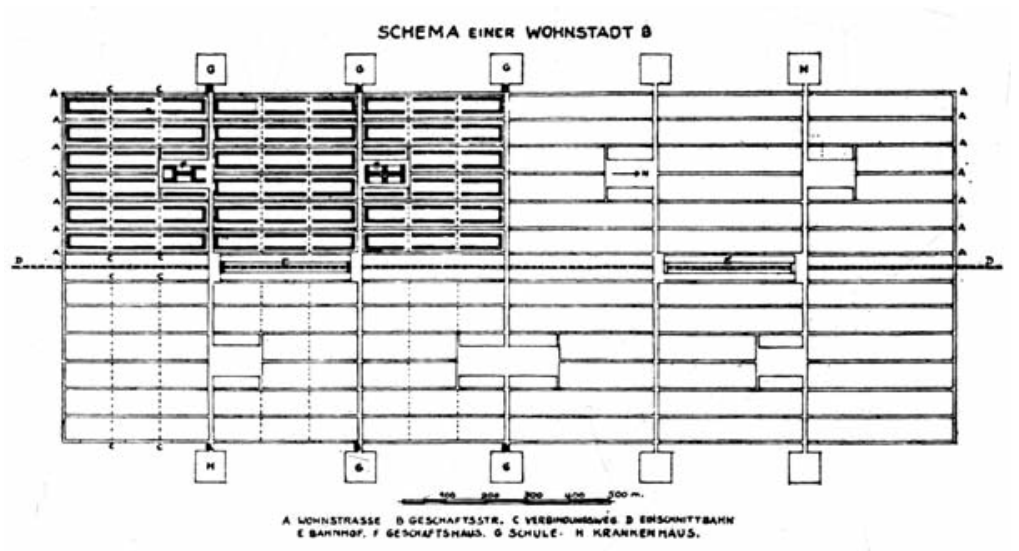

Figura 1. Wohnstadt. Planta. (AIC)

Abajo derecha. Figura 2. Wohnstadt. Calle este-oeste. (AIC)

José Antonio Sumay Arquitecto por la Escuela de Arquitectura de la Universidade da Coruña. Profesor de Civil de la

Consellería de Educación. Xunta de Galicia. tiempo, Hilberseimer elaboró una intensa revisión de sus investigaciones previas sobre la metrópoli moderna para transformarla en un modelo más difuso e integrado con el territorio, la New City, que alcanzará su pleno desarrollo en la etapa del exilio americano.

Los estudios que conducen a Hilberseimer a la generación de un nuevo modelo urbano, la Rey. Doctor Edificación y Obra
New City, parten del cuestionamiento de los modelos precedentes, elaborados en la primera mitad de la década de 1920: la Wohnstadt y la Hochhausstadt. ${ }^{1}$ La Wohnstadt (figura 1 y 2) es un modelo para una ciudad satélite de 125.000 habitantes vinculada a una red de transporte metropolitano y con la residencia como tema principal que Hilberseimer desarrolla a partir de un concurso de la revista Bauwelt en 1923 (Hilberseimer 1924). La Hochhausstadt (figura 3) es un modelo para el área central de la metrópoli y se elabora a finales de 1924 al término de un viaje por Europa donde Hilberseimer tiene la oportunidad de conocer en París la Ville Radieuse de Le Corbusier. ${ }^{2}$

El inicio de este período de revisión e investigación comienza en 1927, fecha de la publicación de su libro La arquitectura de la gran ciudad y su participación en la Weißenhofsiedlung en Stuttgart, y remata en agosto de 1938 cuando viaja a América para aceptar la oferta de Mies van der Rohe para ser profesor en el Armour Institute of Technology de Chicago. Especialmente fructíferos fueron los años de profesor en la Bauhaus, de 1929 a 1933, donde Hilberseimer publica habitualmente tanto en la revista de la escuela como en Die Form, la publicación oficial de la Deutscher Werkbund.

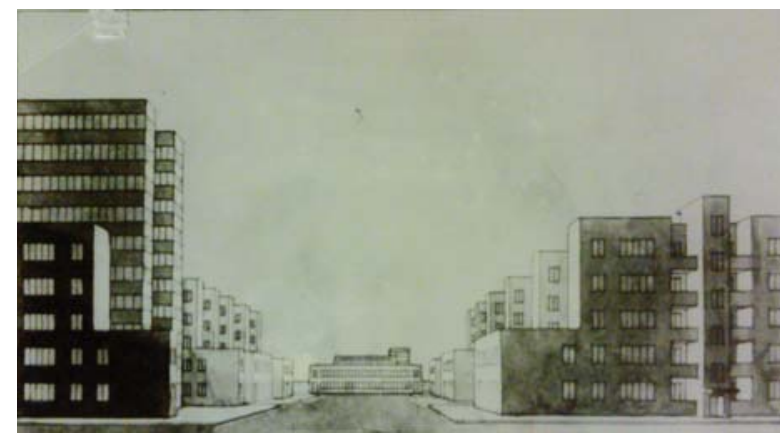




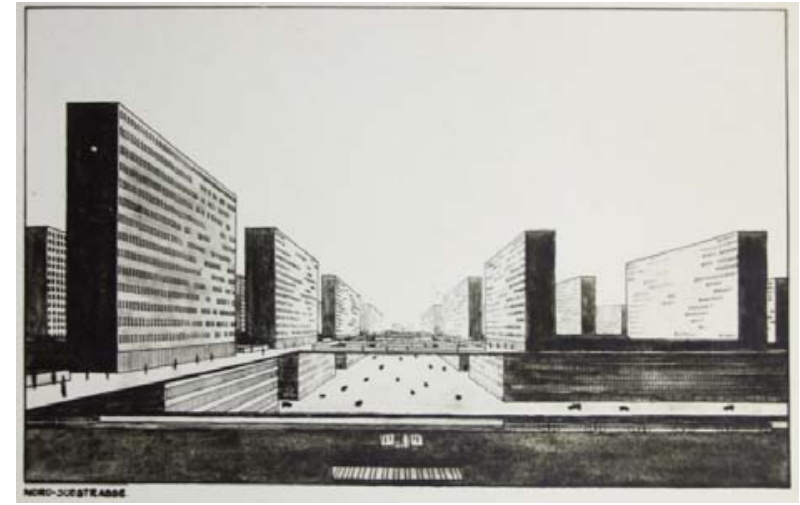

Figura 3.

Hochhausstadt. Calle norte-sur. (AIC))

Figura 4. Linea de montaje.

(Hilberseimer 1949)

Figura 5. Bread line. (Hilberseimer 1949) compactos se produce de una manera pro-
La evolución desde estos primeros modelos gresiva y secuencial, con lineas de separación claras pero sin un abandono definitivo de las investigaciones precedentes. Los ejes sobre los que se articula este cambio son la reflexión sobre la célula habitacional minima, la vivienda y la tipología residencial, el soleamiento y la densidad como parámetros modeladores, la vialidad y el tráfico como el elemento esencial de la condición metropolitana y la relación con el entorno que entronca con la cuestión de la planificación territorial.

\section{Sociedad, familia y vivienda}

Los modelos de Hilberseimer están relacionados con el concepto de metrópoli establecido por Georg Simmel en su ensayo Las metrópolis y la vida del espiritu (1903) (Cacciari 1972). La naturaleza de la metrópoli de Simmel tiene un carácter material, ya que es la sede de la economía monetaria y esta acumulación de capital es la causa de una transformación de la ciudad, no sólo en su morfología urbana, sino específicamente en su naturaleza social y en la condiciones de vida de sus habitantes. En ese sentido, el crack del 29 y la Gran Depresión, la primera gran crisis del sistema capitalista soporte de la metrópoli es determinante en la transformación de los primeros modelos urbanos de Hilberseimer: "La crisis económica mundial, y la nueva orientación económica resultante, pone en cuestión el desarrollo futuro de la ciudad. La crisis nos demostró con claridad que los errores presentes en nuestra estructura urbana pueden llevar a un mayor peligro para la totalidad del tejido social" (Hilberseimer 1940: 100). La Gran Depresión transforma el sistema económico que pasa de ser un modelo fordiano basado en la acumulación de mano de obra en grandes espacios, a uno descentralizado, en el que el proletariado es dividido en unidades productivas más pequeñas, atenuando la posibilidad de una revolución bolchevique (Aureli 2011). Esta sociedad posfordiana, de trabajadores urbanos precarios, encuentra en la huida de la metrópoli una vía para paliar los gravísimos problemas que había que sobrellevar en la ciudad. En la Alemania de 1930, la elevada tasa de paro, por encima del $30 \%$, y la reducción de la protección social en un estado ahogado por las deudas, hacian insostenible para amplias capas de la población la vida en la metrópoli. ${ }^{3}$

En este contexto es significativo la asociación que Hilberseimer establece entre la línea de montaje de una factoría y las bread lines de los desempleados que tienen que recurrir a la caridad para subsistir (figura 4 y 5). La Gran Depresión había demostrado la fragilidad de un sistema económico cuyo producto, la metrópoli, también se habia visto afectada. Este carácter económico y social de la metrópoli impone un nuevo rol para el arquitecto moderno; la formalización de la arquitectura y la ciudad, la definición de los objetos, ya no es la tarea específica del arquitecto que se transforma en desvelar y organizar la naturaleza productiva de la metrópoli (Tafuri 1980).

Hilberseimer busca un modelo urbano que dé respuestas a las nuevas demandas sociales y condiciones económicas; esto se logra disolviendo el fundamento cognitivo de la metrópoli, la Nervenleben (vida excitada) de Simmel, por medio del uso de la
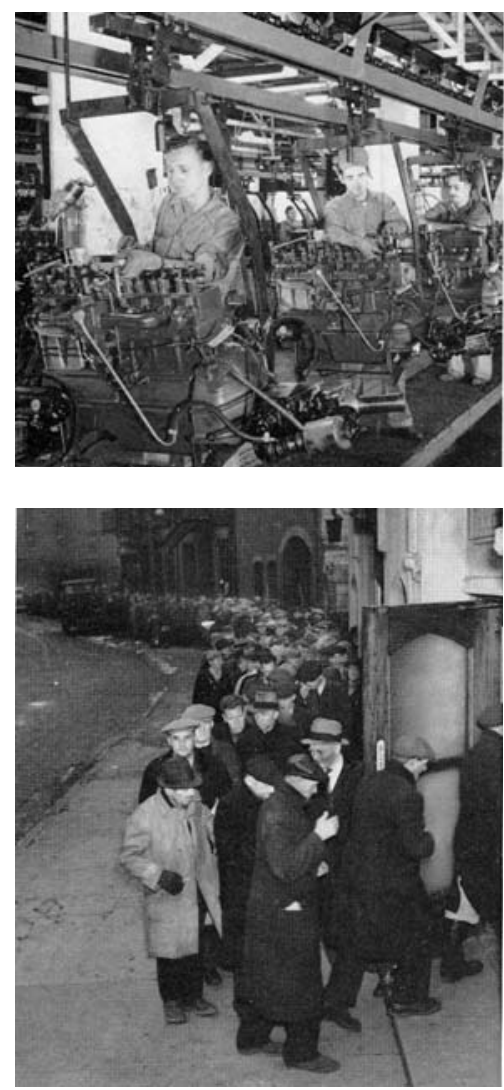
vivienda unifamiliar y su inserción en el paisaje: los ciudadanos dispondrán de una pequeña parcela en la proximidad al entorno natural para neutralizar la vida fugaz de la metrópoli. Hilberseimer opta también por entidades de población más pequeñas en las que se restableceria un cierto sentimiento de comunidad, con servicios y espacios de reunión propios, limitando el carácter metropolitano de esta sociedad. 4 A pesar de que con estas determinaciones se pretende restringir el carácter metropolitano de la ciudad, lo que consigue es mejorar las condiciones de sus habitantes sin cuestionar su fundamento productivo.

El abandono de la idea de metrópoli compacta implica el distanciamiento de Hilberseimer hacia el sistema económico capitalista causante de la Gran Depresión acercándose a un modelo social más próximo a las comunidades rurales autosuficientes que describió el anarquista Piotr Kropotkin (1898) así como a los modelos rurbanos de Soria (1894) o Howard (1898): "la ciudad debe asumir un carácter más agrícola y el campo un carácter más urbano. El campo debe integrarse en la ciudad y ésta constituir una parte misma del campo" (Hilberseimer 1963: 24-25).

\section{Familia y vivienda}

Si la metrópoli se refiere a la sociedad, la vivienda se relaciona con la estructura familiar y las nuevas formas de habitar. Hilberseimer se remonta al cambio social que provoca la desaparición de la gran familia patriarcal tradicional transformada en la familia nuclear característica de la sociedad moderna (Hilberseimer 1928). Este tipo de familia se asociaba con la gran vivienda, un espacio donde se vivía y trabajaba, compartido por la familia en múltiples actividades que iban desde el trabajo al descanso, pero sin olvidar también el cuidado y formación de los niños que habitualmente se realizaba en el hogar. Esta casa era el gran contenedor que resolvía todas las necesidades del individuo en el seno de la familia. La industrialización, con la concentración de la fuerza productiva en fábricas y talleres provoca, según Hilberseimer, el cambio más radical en la configuración de la vivienda: se produce su especialización funcional a la vez que disminuye significativamente su tamaño y aparecen estancias segregadas de ese espacio común primitivo como son la cocina y el baño.

Pero estos procesos también han contribuido a transformar la estructura urbana; la separación de los lugares de trabajo y de habitación traslada a la estructura de la metrópoli unos procesos que hasta ese momento estaban contenidos en los limites de la vivienda, generando un nivel de tráfico que, aun a pesar de la irrupción de los modernos medios de transporte y comunicación, pondrá la ciudad tradicional al borde del colapso. La solución reside, en opinión de Hilberseimer, en retomar el tipo de la vivienda unifamiliar como tipología residencial urbana preferente para las familias con hijos y que expone en un breve programa: "La sociedad debe ofrecer, al menos, a cada individuo una habitación propia, y para la familia, además de todos los espacios comunes (cocina, cuarto de baño), una sala amueblada en relación con el jardín" (Hilberseimer 1928). Los bloques y torres de apartamentos se reservan para personas solas o parejas jóvenes con menor demanda de espacio libre.

Hilberseimer despeja las dudas sobre la viabilidad económica de la edificación en planta baja como tipología adecuada para la vivienda social, argumentando que su mayor coste en la urbanización se vería compensado por su simplicidad constructiva y porque permitiria una densidad elevada controlada a través de la limitación del frente de fachada y la ocupación del fondo de la parcela (Hilberseimer 1929).

Esta tipología ya había sido estudiada por Hilberseimer en la primera mitad de la década de 1920, las Reihenhäuser (casas en hilera) o el proyecto para BerlínRuhleben de 1925 (figura 6), inspiradas en
Figura 6. Proyecto de casas en hilera para Berlin-Ruhleben (1925)

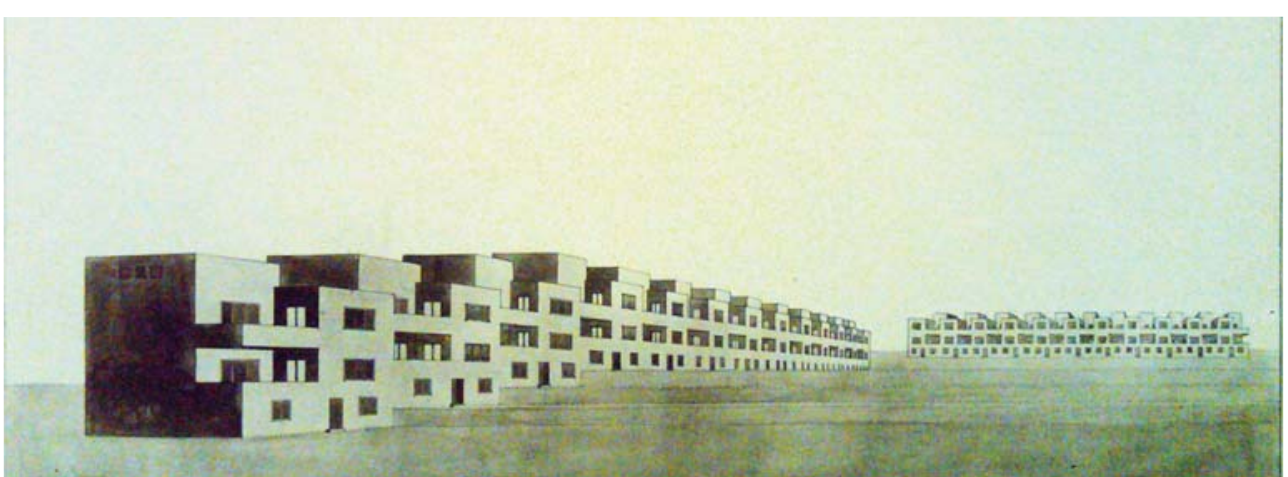


Izquierda.Figura 7. Vivienda en hilera de dos plantas, frente de 5 y $6 m$ (1929)

Izquierda.Figura 8. Vivienda en $L$, frente de 10.5 y $8 m$ (1929)
Figura 9. Vivienda en $L$ (1929). (AIC)
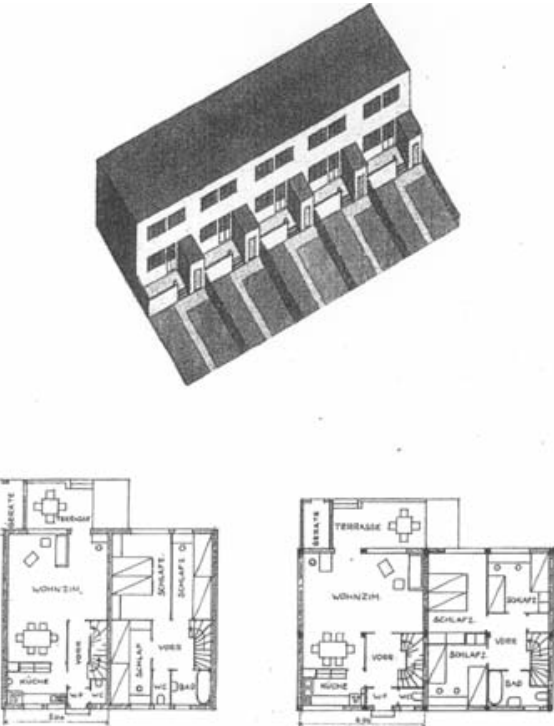

los ejemplos de J.J.P. Oud (Pommer Spaeth y Harrington 1988). Estos estudios se fundamentan también en las propuestas de Peter Behrens y Heinrich de Fries (1918), con edificación agrupada en peine, que aumenta la densidad sin aumentar la longitud del viario y por lo tanto los costes de urbanización, e incluso en la casa sin ventanas de su amigo Hugo Häring, por cuanto resuelve la vivienda por medio de luz cenital y con una alta ocupación en planta (Hilberseimer 1927).

En 1929, Hilberseimer publica Großstadtische Kleinwohnungen (Las viviendas minimas en la metrópoli) pretendiendo despejar las dudas sobre la vivienda unifamiliar pues, en ese momento, un $65 \%$ de las familias prefieren una vivienda en edificación colectiva frente al 35\% que optan por una unifamiliar. La razón de esta situación, en su opinión, se debe a que se construyen viviendas muy pequeñas que, para minimizar los costes de urbanización, reducen al limite el frente edificado y reparten su limitada superficie en tres o

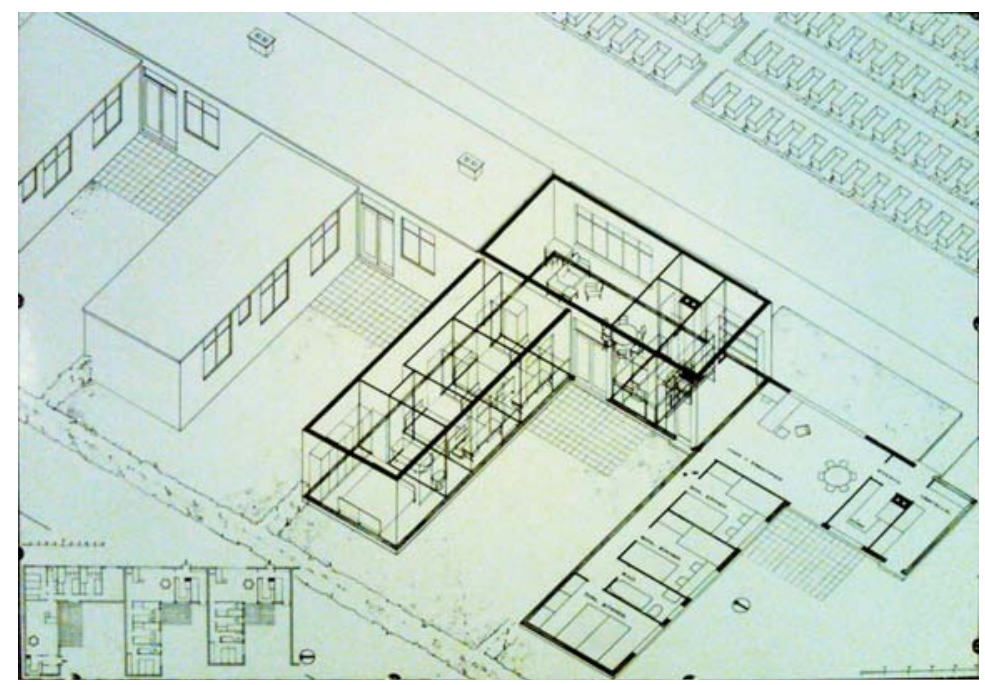

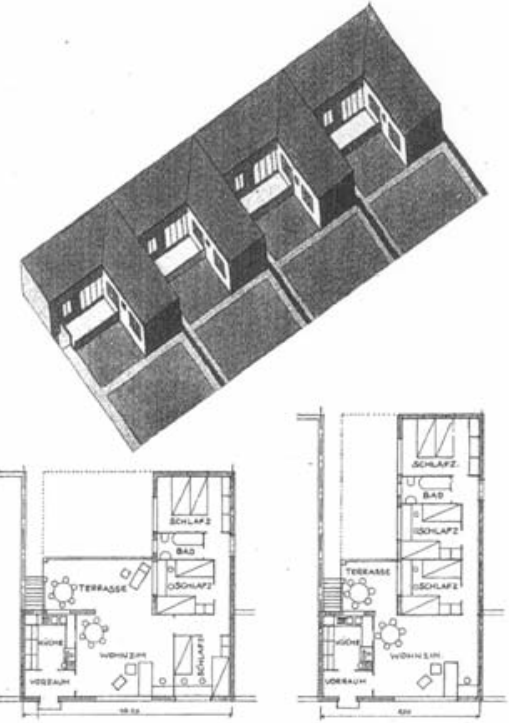

cuatro plantas obteniendo como resultado unas distribuciones interiores inapropiadas. Con el fin de justificar gráficamente la idoneidad de la vivienda unifa-

miliar Hilberseimer analiza dos viviendas minimas adosadas de superficie inferior a $80 \mathrm{~m} 2$ con dos tipologías para diferentes frentes: la casa en dos plantas (figura 7) y la vivienda en L en una planta (figura 8) (Hilberseimer 1929).

Este estudio es el punto de partida de la conocida casa con patio de Hilberseimer que se organiza en una planta con una configuración en L, con la cocina y estar dispuestos longitudinalmente sobre la calle de acceso y el área de noche perpendicular a esta crujia, penetrando sobre la parcela, a la vez que deja un pequeño patio sobre el que ventilan los dormitorios y cuarto de baño. Aunque logra una tipología de elevada densidad, la crujía de los dormitorios ocupa el patio, reduciéndolo a un espacio angosto e insuficientemente soleado, a la vez que limita el acceso que a este patio debe tener el área de día que se relacionará principalmente a través de una terraza (figura 9). Pero el tipo edificatorio ha quedado ya determinado en este nivel primario de la investigación; las soluciones que se van a dar a la problemática de soleamiento y ventilación serán precisamente las que determinarán la transformación y mejora del tipo, pero sin variar sustancialmente sus elementos característicos.

Vivienda colectiva y Mischbebauung (Urbanización mixta)

En cuanto a la vivienda colectiva Hilberseimer analiza tres tipologias: la Mietshaus (vivienda de alquiler), la Laubenganghaus (vivienda corredor) y la Apartmenthaus (casa de apartamentos). 
Figura 10. Tipificación de la vivienda en la Mietshaus. (Hilberseimer 1929)

Figura 11. Combinación de viviendas en la Mietshaus. (Hilberseimer 1929)

Abajo izquierda. Figura 12. Detalle de las viviendas. Laubenganghaus. (Hilberseimer 1929)

Abajo derecha. Figura 13. Planta general. Laubenganghaus.

(Hilberseimer 1929)
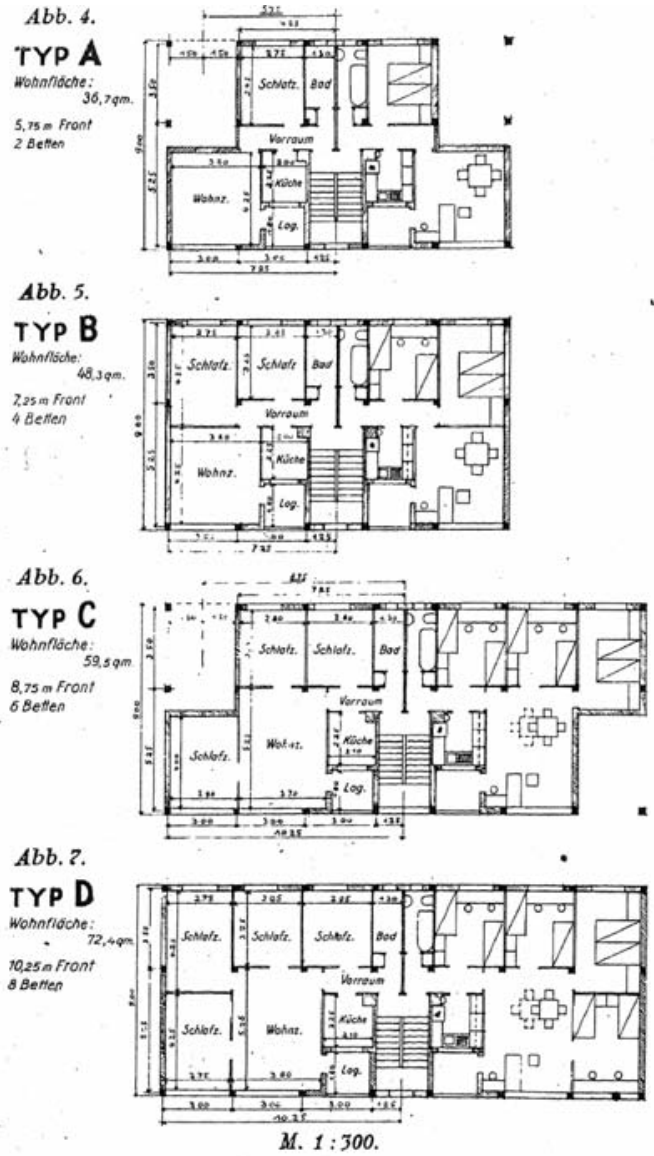

La Mietshaus o vivienda colectiva de alquiler (figura 10) proviene de la tipología ya utilizada en la Wohnstadt. Su morfología responde a la de bloque laminar, contenedor de viviendas de varios dormitorios, que dispone de un núcleo de escaleras cada dos viviendas, iluminadas y ventiladas por ambas fachadas. Hilberseimer evoluciona a partir de este bloque manteniendo la distribución de la planta y aumentando la variedad de viviendas de dos a ocho camas. También analiza dimensionalmente la planta buscando una combinación óptima de distancia entre escaleras y modularidad de las viviendas, con el fin de conseguir su estandarización, un proceso previo a la industrialización del proceso constructivo necesario para mejorar la viabilidad económica de la construcción (figura 11).

La Laubenganghaus es un bloque de vivienda en corredor para apartamentos de una, dos y cuatro camas (figura $12 \mathrm{y}$ 13). Dispone de dos bloques de comunicaciones verticales y una cubierta plana que sirve de terraza jardín para uso privado mientras que la planta baja se dedica a salas de reuniones. Aunque en los estudios previos es de cuatro plantas, los modelos posteriores aumentan la altura a 10 plantas hasta llegar a unas 140 unidades de vivienda. Al igual que en el bloque laminar los espacios de las viviendas se modulan a $3.10 \mathrm{~m}$. para facilitar su estandarización en previsión de una prefabricación futura que abaratase el proceso constructivo.

La Apartmenthaus o boarding house 5 es un tipo edificatorio nuevo importado de la realidad norteamericana y que Hilberseimer caracteriza como rascacielos en $\mathrm{T}$ de 10 a 15 plantas, a medio camino entre una vivienda y un hotel. Los servicios principales están centralizados con cocina y restaurante, así como salones comunes y administración (figura 14). De la composición de estas tipologías residenciales colectivas con las viviendas unifamiliares en planta baja, Hilberseimer genera

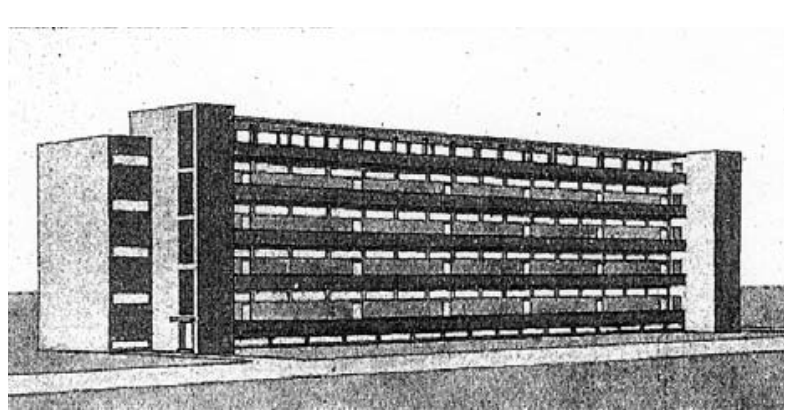

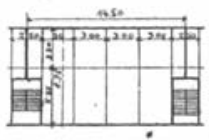
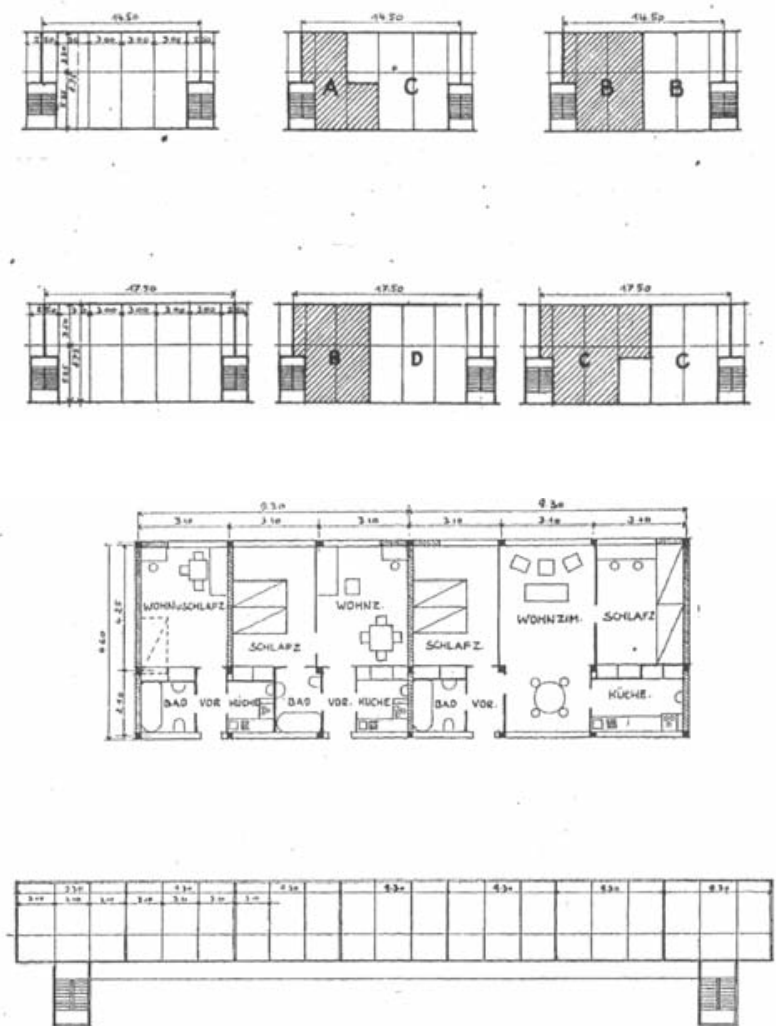
Derecha. Figura 14. Planta de Apartmenthaus y detalle de las viviendas.

(Hilberseimer 1929)

Figura 15. Estudios de la Mischbebauung (c. 1930). (AIC) Soleamiento de la Mischbebauung (c. 1930). (AIC)

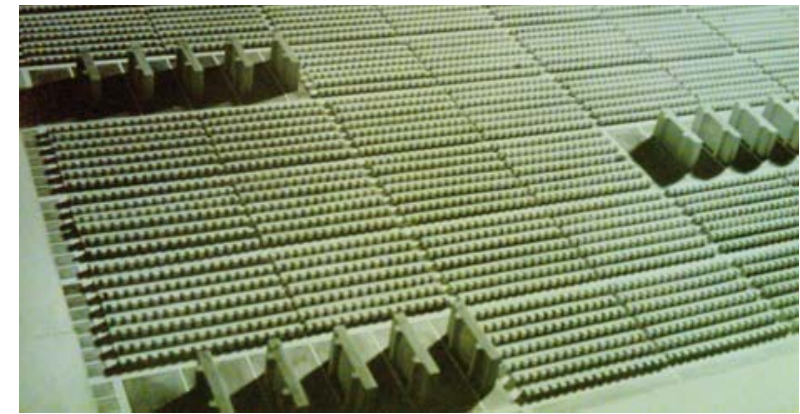

unos estudios de nuevos tejidos urbanos que integran vivienda unifamiliar y colectiva manteniendo una densidad elevada y en las que no se ha disuelto la relación entre la manzana y el viario, es la Mischbebauung. ${ }^{6}$ La Mischbebauung (urbanización mixta) es un conjunto de estudios tipológicos y sobre el tejido urbano que ayudan a conformar un modelo de ciudad jardín densa basada en tres pilares fundamentales: la alternancia HochbauFlachbau (edificación alta y baja), la densidad elevada ${ }^{7}$ y el soleamiento óptimo (figura 15). ${ }^{8}$

\section{Soleamiento y densidad}

Aunque ya en la Hochhausstadt y la Wohnstadt habian presentado una disposición de la edificación que buscaba la adecuación a los criterios heliotérmicos, estas inquietudes estaban minimizadas
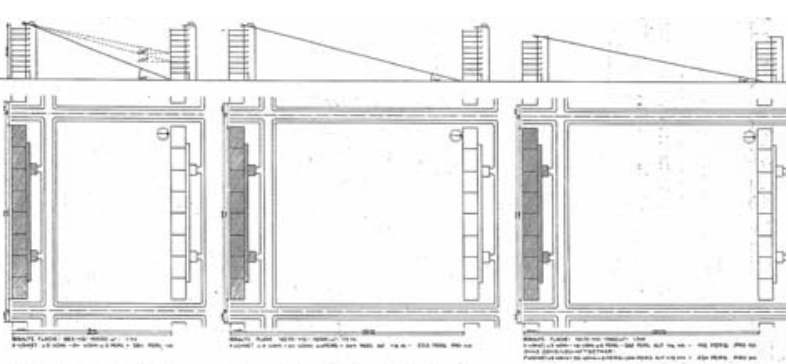

Figura 17. Comparació $n$ de densidades entre Flachbau y Hochbau (1931). (Hilberseim er 1931c)
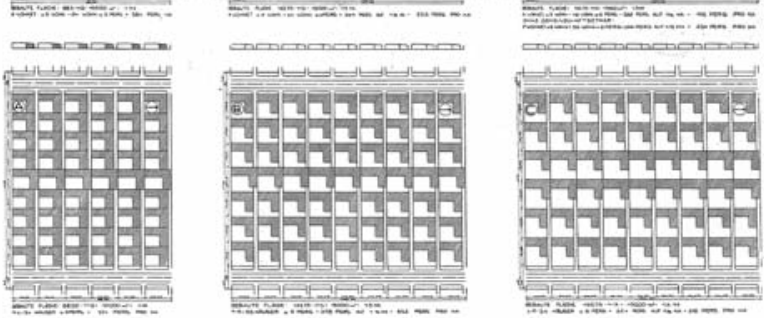

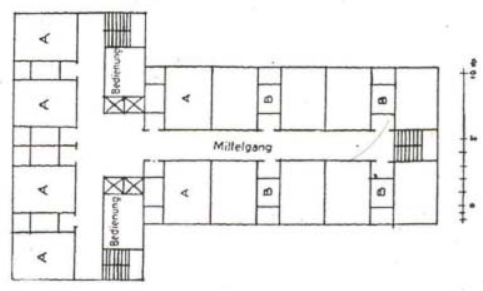

por una mayor presencia de la circulación y el análisis del tipo edificatorio. En ausencia de unos elementos compositivos geométricos o visuales a los que se renuncia en busca de una mayor objetividad y carácter científico, Hilberseimer utiliza el soleamiento como elemento de objetivación de la Mischbebauung (figura 16).

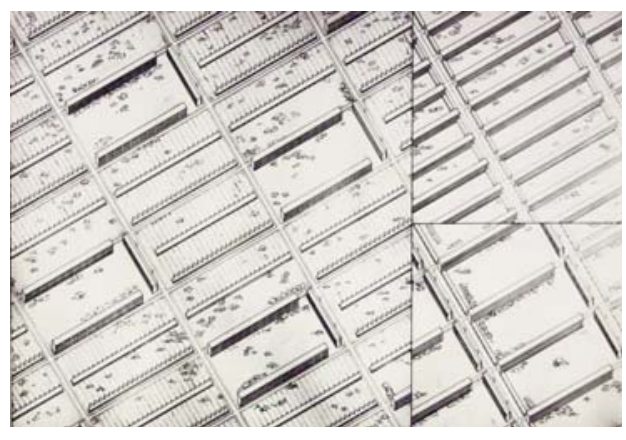

La Mischbebauung abre un período en el que se profundiza en la influencia del soleamiento en la morfología de la vivienda y las propuestas urbanas y su relación con los factores económicos de la urbanización. Estas investigaciones trascienden el mero análisis de soleamiento de fachada para estudiar el soleamiento en el interior de la vivienda y sus consecuencias en la forma urbana. Hilberseimer relaciona tipologia, densidad y soleamiento sobre una superficie de una hectárea, planteando como árbitro de la disputa entre vivienda unifamiliar y colectiva unas condiciones de soleamiento y densidad homogéneas (figura 17) (Hilberseimer 1931c).

Hilberseimer admite el mayor coste de la solución propuesta, a pesar de la simplificación constructiva, con respecto a la ciudad tradicional, pero también demuestra la capacidad del urbanismo moderno para lograr densidades próximas a las de Berlin ${ }^{9}$ garantizando un soleamiento óptimo de las viviendas. Concluye también que será la dispersión, abandonando las altas densidades, y una mayor integración de la ciudad en el territorio la vía para la solución a los problemas de la metrópoli. Este proceso de Auflockerung (esponjamiento), del tejido residencial se caracteriza por la inclusión del espacio verde en el 
Izquierda. Figura 18 Inclusión del espacio verde en la Mischbebauung (1931). (AIC)

Derecha, Figura 19 Soleamiento de una estancia (c. 1935). (AIC)

Figura 20. Relación entre $n^{\circ}$ de plantas $y$ densidad.

(Hilberseimer 1936)

Figura 21. Influencia de la forma de la cubierta en la densidad. (Hilberseimer 1936)

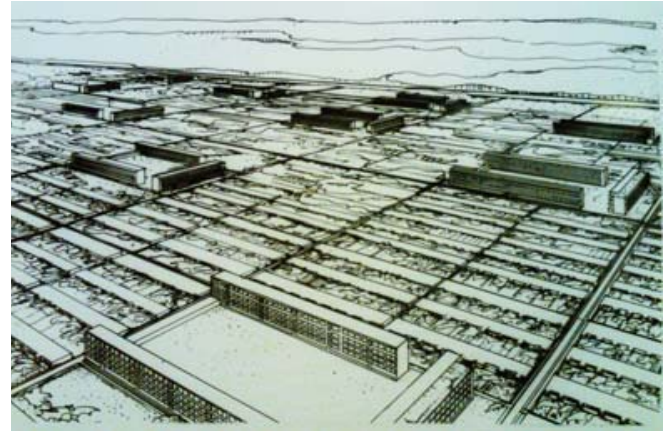

interior de la manzana a escala edificatoria, buscando mejorar la relación de la metrópoli con su entorno (figura 18). 10

Los últimos trabajos que publica en Alemania constituyen pormenorizadas investigaciones sobre la influencia en el soleamiento de la orientación de las estancias y la relación entre soleamiento y densidad en la urbanización (Hilberseimer 1935; Hilberseimer11 1936). Con ellos inicia el estudio de la naturaleza física de la luz solar y su composición en diferentes tipos de radiaciones, luz visible, infrarroja y ultravioleta y sus importantes funciones para la vida. La finalidad de un correcto soleamiento de los espacios se corresponde, no tanto con la intensidad como con la profundidad del haz de luz sobre los paramentos de la estancia. No se revisa el conjunto de la edificación sino la célula habitacional mínima, con una misma disposición de mobiliario y huecos; se verifica la incidencia de la luz solar sobre los paramentos de la estancia y se evalúa no sólo la superficie soleada sino el volumen del prisma de soleamiento (figura 19).

Analizado el soleamiento en las estancias, Hilberseimer estudia la influencia en el diseño de ciudades relacionando orientación con densidad urbana y latitud (Hilberseimer 1936). La conclusión principal es el descubrimiento de la falacia del edificio en altura que supone derribar el mito que vincula densidad con edificación en altura. Hilberseimer demuestra que, con condiciones de soleamiento homogéneas, el aumento de la altura de la edificación no implica un aumento significativo de la densidad (figura 20), situación que se acentúa según aumenta la latitud. 12 Esta investigación afianza la decisión de

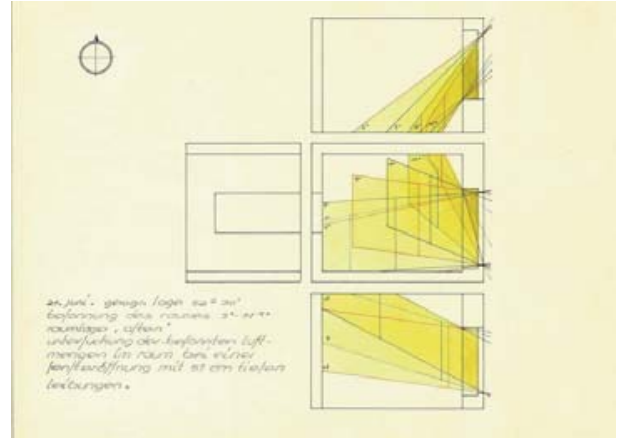

Hilberseimer de tomar la vivienda unifamiliar como tipo prioritario para el tejido residencial de la New City; pero tampoco se puede entender como un abandono definitivo de la edificación en altura ya que ésta seguirá teniendo su importancia para el nuevo modelo aunque ya no asociado a la trama sino aislado, vinculado a la infraestructura y la naturaleza (Sumay 2014).

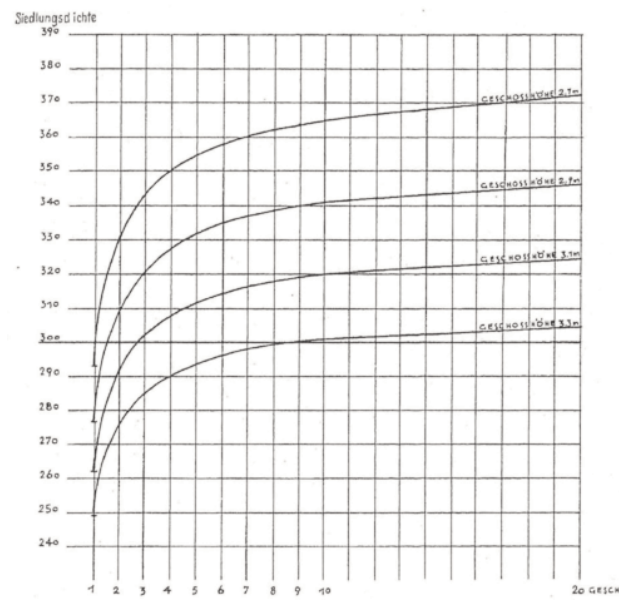

Pero estos estudios de soleamiento no sólo tienen una influencia sobre la forma urbana sino que también es una ley compositiva de la arquitectura moderna en el uso de la cubierta plana. Hilberseimer justifica su utilización como un elemento que permite un aumento del $50 \%$ de la densidad edificatoria manteniendo el mismo soleamiento que una vivienda con cubierta inclinada (figura 21). La alternativa entre soluciones constructivas no se toma ya desde criterios compositivos sino que se ha objetivado como la solución óptima que permite una urbanización más densa y por lo tanto más económica.

\section{Espacio doméstico y prefabricación}

En el proceso de análisis de la metrópoli, Hilberseimer llega a la mínima entidad de la vivienda: la estancia. Del estudio de organización de ésta, por agregación, se desarrolla la vivienda, el bloque edificatorio y la ciudad entera (Hilberseimer 1927). 


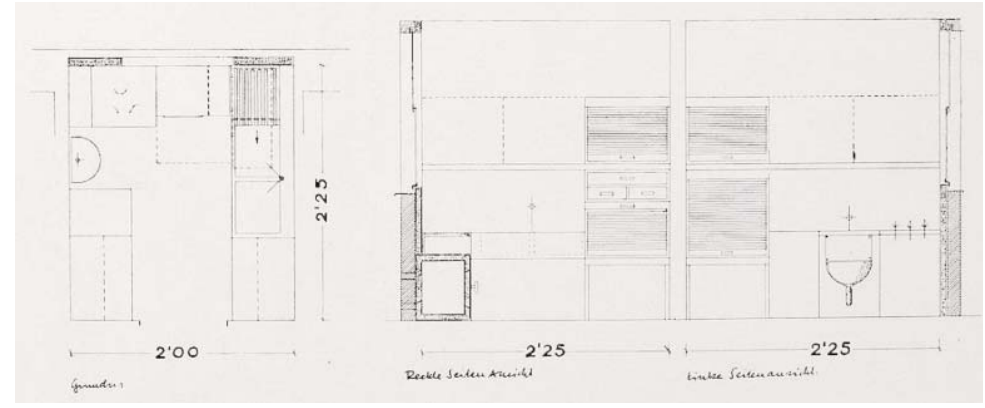

Figura 22. Planta $y$ secciones del prototipo R1 (1928). (Simmel 1929).

En ese discurso sobre la vivienda mínima, la economía de la misma pasa por el control de la dimensión de sus componentes a través de la definición de su mobiliario y su organización espacial, con una superficie total muy inferior a estándares posteriores, pero que permitirian una vida digna para un numeroso grupo de población. Estos trabajos son el punto máximo de objetivación de la vida doméstica al presuponer la universalidad en las demandas de los habitantes hacia el mobiliario y los espacios de la casa.

En esta línea podemos entender la participación de Hilberseimer junto a Hugo Häring en la exposición organizada por la Arbeitsgemeinschaft für deutsche Handwerkskultur (Círculo de estudios para la cultura alemana de la artesanía) y Der Ring en 1928 sobre la cocina, elaborando dos prototipos de cocina, R1 y R2 de 4.5 y $8.3 \mathrm{~m} 2$ respectivamente, para vivienda mínima en un bloque laminar. Esta investigación sobre la cocina no se queda en mero estudio funcional o constructivo sino que, en la metodología de Hilberseimer, tiene implicaciones en la dimensión de la vivienda y la ciudad. Según Alice Simmel la Berliner Wohnungsfürsorgegesellschaft (Sociedad berlinesa para la protección de la vivienda) establecía una superficie minima de coci-

Izquierda. Figura 23. Plantas de la vivienda unifamiliar y el apartamento.

Exposición Die Wohnung unserer Zeit (1931). (Hilberseimer 1931b)

Derecha, Figura 24. Espacio de trabajo incorporado al estar. Exposición Die Wohnung unserer Zeit (1931). (Hilberseimer 1931b)
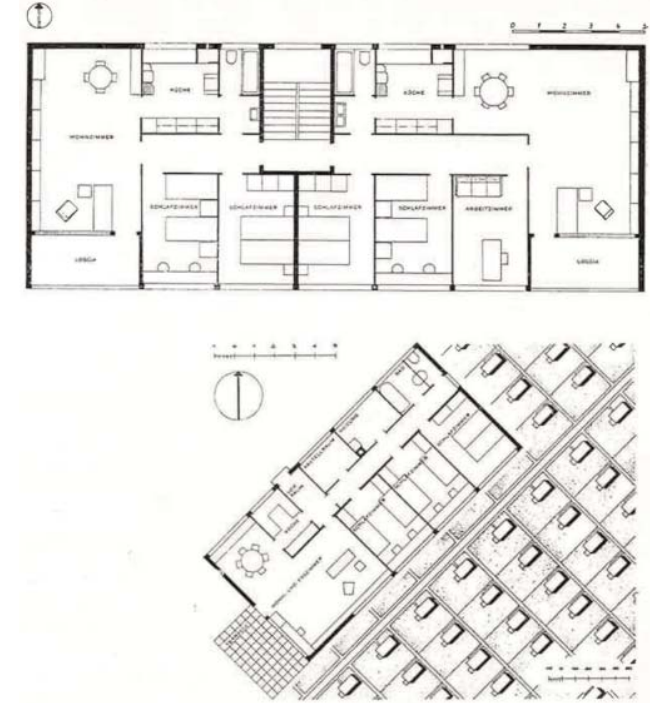

na de $10 \mathrm{~m} 2$ con lo cual el prototipo R1 podria ahorrar $5.5 \mathrm{~m} 2$ por vivienda (figura 22). Trasladado este ahorro a la producción anual de 25.000 viviendas en Berlín, supondría la construcción de 2000 viviendas más, o un aumento proporcional en el resto de espacios de la vivienda. (Simmel 1929)

En 1931 Hilberseimer tendrá en Die Wohnung unserer Zeit (La vivienda de nuestro tiempo), una sección de la Deutsche Bauausstellung (Exposición alemana de arquitectura) en Berlín, la posibilidad de estudiar el amueblamiento de la vivienda social y la estricta configuración dimensional de las estancias (Hilberseimer 1931a; Hilberseimer 1931b). De estos estudios se destaca la continuidad entre vivienda en bloque y la vivienda unifamiliar de una planta, pues Hilberseimer presenta la posibilidad de amueblar las unifamiliares con los mismos criterios de la edificación colectiva (figura 23). También es importante la incorporación del espacio del trabajo a la vivienda con lo que se produce la descomposición del salón (Wohnzimmer) en estar, comedor y despacho (Wohnplatz, Eßplatz und Arbeitsplatz) (figura 24). Esta incorporación del espacio del trabajo a la vivienda tiene que ver con las condiciones económicas posteriores a la crisis del 29 y anticipan las posibilidades que el trabajo en casa traerán al modelo de metrópoli difusa que representa la New City.

En 1932, Hilberseimer participa en la exposición, organizada Martin Wagner, Das wachsende Haus (La casa que crece) que, bajo el lema Sonne, Luft und Haus für Alle (Sol, aire y vivienda para todos) se celebra entre 14 de mayo al 7 de agosto en el recinto ferial de Berlín-Charlottenburg y plantea las posibilidades de prefabricación y ampliación de la vivienda unifamiliar en planta baja. A partir de un concurso previo convocado en 1931, la exposición cuenta

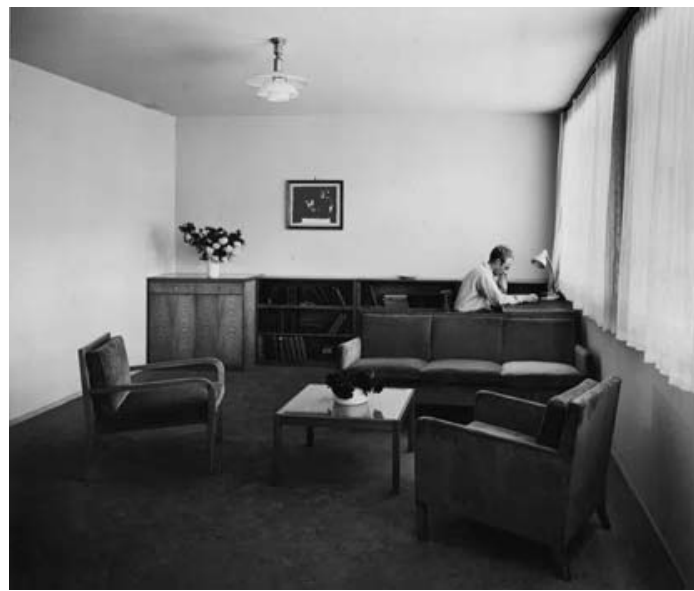


Figura 25.

Planta de Das wachsende Haus (1932). (Hilberseimer 1932a)

Derecha. Figura 26. Fotomontaje de Das wachsende Haus (1932). (AIC)

Derecha. Figura 27. Vista exterior de Das wachsende Haus (1932). (AIC)

Figura 28. Vista exterior de Das wachsende Haus (1932). (AIC)

Figura 29. Vista del estar-comedor de Das wachsende Haus (1932). (AIC)

(1)

\section{ARCHITEKT: LUDWIG HILBERSEIMER}
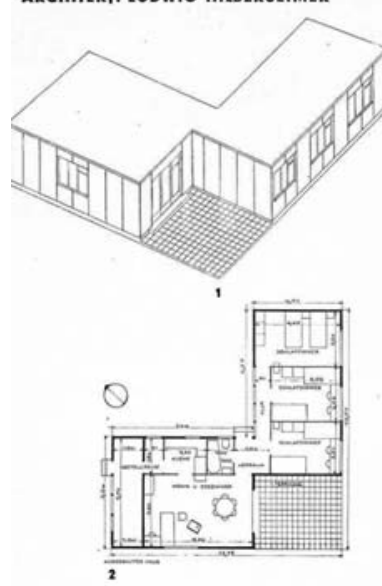

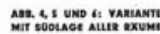
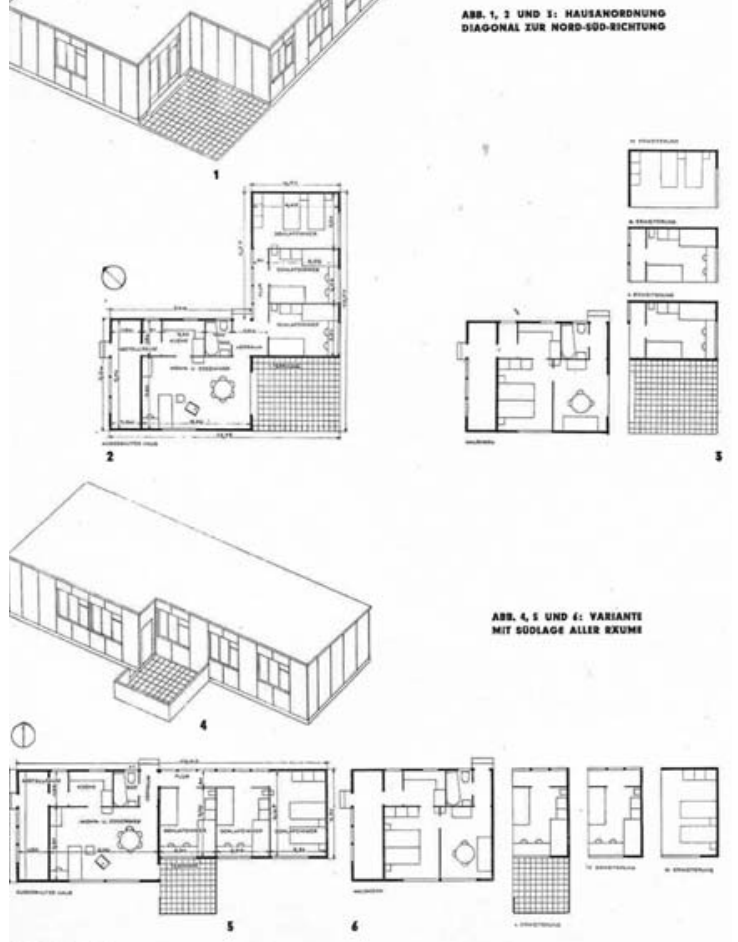

con la participación de Wagner y Hiberseimer así como Hans Schauron, Otto Bartning o Bruno Taut en el diseño y la construcción de un prototipo de la Das wachsende Haus.

La vivienda de Hilberseimer, en colaboración con Pius Pahl alumno de la Bauhaus, desarrolla la tipología de crujía simple y vivienda en $\mathrm{L}$ articulada en torno a una terraza (figura 25 a 29) (Hilberseimer 1932b). En este proyecto se expresan los estudios de modularidad sobre la unidad básica, la estancia. La edificación se inicia con el Hauskern, el núcleo de la casa, que contiene la cocina, el baño y una estancia que puede ser dividida en un dormitorio y una sala de estar. Partiendo de este núcleo la casa crece añadiéndole los módulos con los dormitorios según las necesidades de los propietarios (Wagner 1932).

La propuesta pretende adaptarse a la nueva realidad social y económica surgida de la crisis del 29,13 con un proletariado urbano que huye de la ciudad hacia el campo buscando un medio de subsistencia que la ciudad no le proporciona (figura 30). Las perspectivas de la implantación de la vivienda en el entorno nos muestran cómo en la parte posterior de la parcela se disponen los cultivos que complementarían la manutención de la familia con un trabajo parcial en la industria o el sector servicios (figura 26). (Hilberseimer 1967a) La respuesta para esta nueva época es una arquitectura sencilla y prefabricada, estrictamente modulada pero con una tecnología que nos hace pensar incluso en la posibilidad de la autoconstrucción: la vivienda se construye por medio de unos paneles de madera de $90 \mathrm{~cm}$. de ancho y con la altura de un piso. La Das wachsende Haus de Hilberseimer supone la materialización de una idea de vivienda mínima, derivada de los estudios de las vivien-
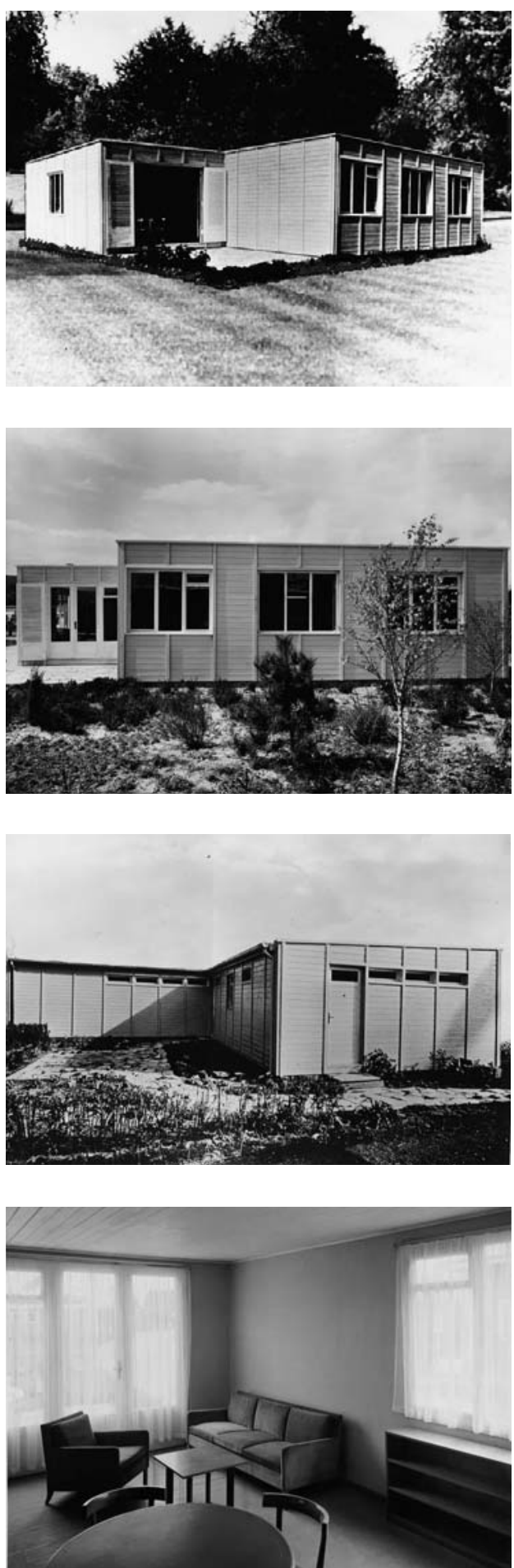


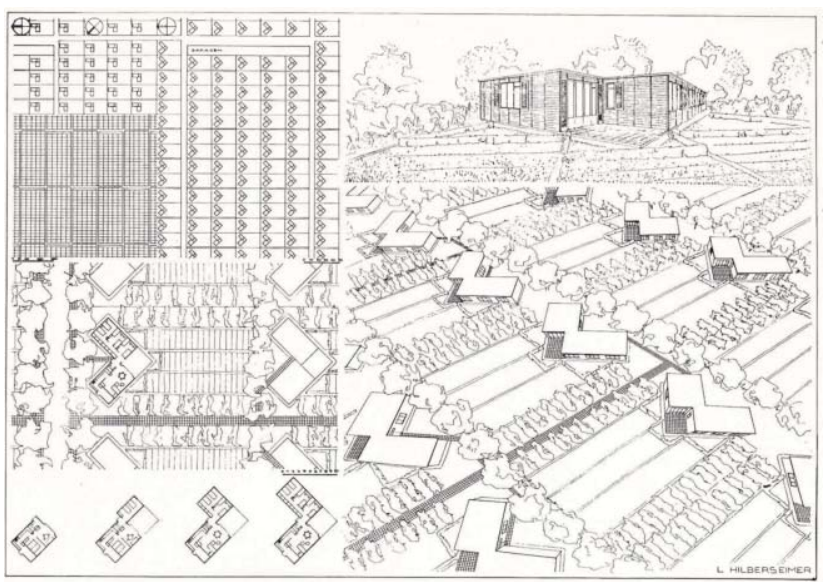

Figura 30. Urbanización con Das wachsende Haus (1932). (Hilberseimer 1932a)

da social en bloque, por medio de la prefabricación de los elementos constructivos que la componen y que es la pieza elemental con la que se compone el modelo de la New City, la nueva metrópoli descentralizada.

\section{Sistema lineal y unidad de asentamien- to}

A principios de los años 30, los estudios de la Mischbebauung se han sistematizado y condensado en torno al tipo residencial y la relación entre forma urbana, densidad y soleamiento. Pero a pesar de esto, la Mischbebauung aún no puede ser considerada un modelo urbano pleno; le falta la estructura urbana general que articule los distintos tejidos (residencial, comercial o industrial) y los integre con las infraestructuras viarias de la metrópoli.

Figura 31.

Combinación de bloques de la Mischbebauung (c. 1933). (AIC)

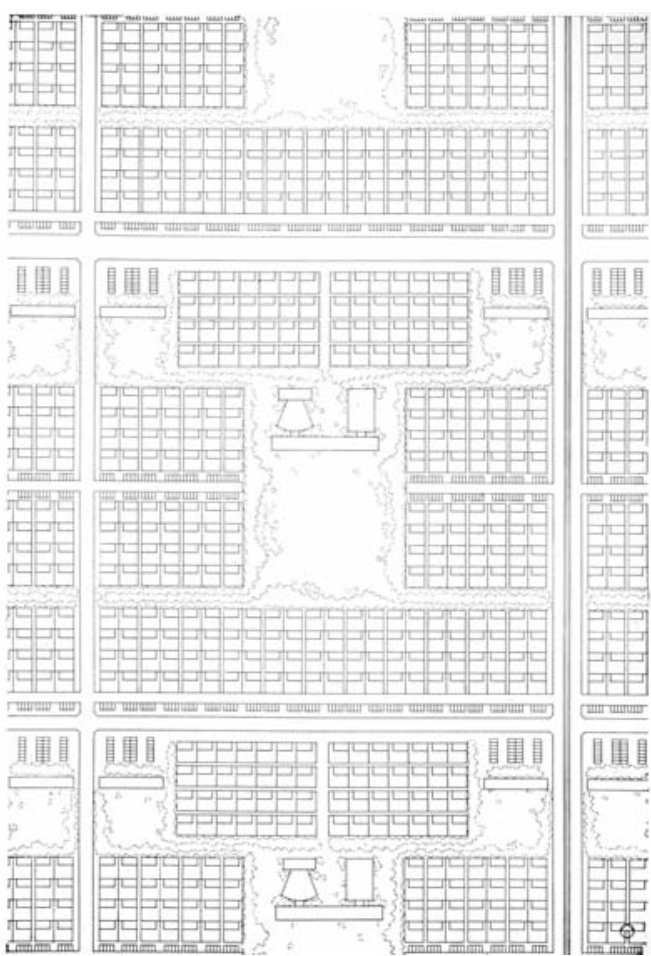

El primer intento de encontrar una estructura urbana para un nuevo modelo se realiza agrupando las manzanas de la Mischbebauung para disminuir el número de intersecciones viarias, a la vez que mejorar las condiciones de la edificación (figura 31). Hilberseimer une las manzanas de la Mischbebauung en grupos de ocho, para reducir el número de intersecciones viarias necesarias y dejar un espacio verde confinado en el centro de la agrupación, que servirá de parque y zona escolar. El acceso a las viviendas es por medio de vías en cul-de-sac con sendas peatonales que comunican la residencia con el espacio verde y la zona escolar. En esta primera tentativa podemos observar algunas de las características que darán lugar a la New City: separación de tráficos peatonal y rodado y vinculación directa entre residencia y espacios verdes; pero en esta propuesta el tráfico todavía no está convenientemente segregado del área residencial y para ello Hilberseimer aumenta la escala de actuación con la finalidad de alejar el viario de la edificación y separar las intersecciones viarias.

\section{La unidad de asentamiento}

La adecuación a las necesidades de la sociedad metropolitana ha llevado a Hilberseimer a la apertura de la idea urbana y el abandono paulatino de los sistemas centrales de organización urbana. Estas claves serán integradas en la unidad de asentamiento, la pieza básica en la composición del nuevo modelo urbano, la New City.

La unidad de asentamiento tiene un tamaño limitado pero contiene todos los elementos necesarios de una ciudad segregados de acuerdo a su función (Hilberseimer 1949). Es una agrupación intermedia entre el entero organismo urbano y la vivienda; se compone de un área residencial en forma de espina de pez con calles en cul-de-sac y un área productiva, con espacios de trabajo y comerciales que se sitúa en las proximidades de la infraestructura viaria a una distancia que permita el acceso peatonal desde el área residencial (figura 32 y 33). Una de las primeras referencias que tenemos es un croquis titulado Die Großstadt als Gartenstadt (La metrópoli como ciudad jardín) (c. 1932) ${ }^{14}$ que supone un primer planteamiento completo del modelo urbano basado en las unidades de asentamiento, en el que ya podemos apreciar todos los elementos fundamentales: infraestructura viaria, estructura en espina de pez y cul-de-sac, ubicación de las áreas comerciales y de las 

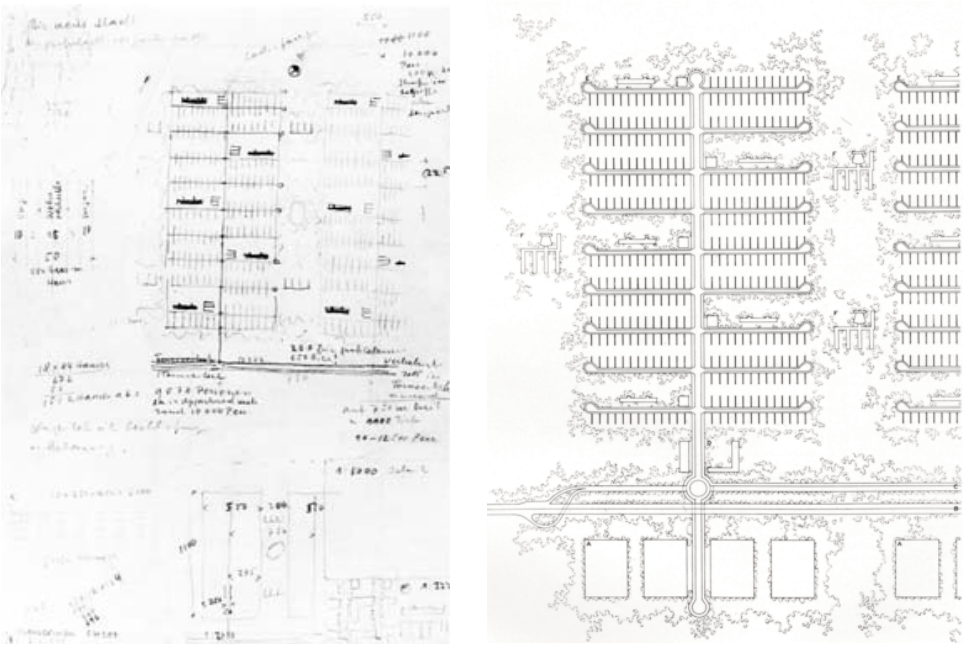

Izquierda. Figura 32. Die Großstadt als Gartenstadt (c. 1932). (AIC)

Derecha. Figura 33. Unidad de asentamiento (c. 1932). (Hilberseimer 1944)

Izquierda. Figura 34. Supermanzana residencial (c. 1932). (AIC)

Derecha. Figura 35. Supermanzana para terciario (c. 1932). (AIC) escuelas y la relación con el espacio natural. En este croquis se incorporan tejidos urbanos de la Mischbebauung y es el documento que sirve de base al trazado de la unidad de asentamiento.

La unidad de asentamiento está, al igual que los modelos anteriores, limitada en su tamaño debido a dos condiciones impuestas por Hilberseimer a sus modelos: la primera y más importante es la necesidad de poder acceder al área de trabajo en una distancia que sea cómoda caminando, en torno a $600-1200 \mathrm{~m}$ desde la vía principal; 15 la otra limitación corresponde con la proporción que Hilberseimer establece en sus modelos entre tejido residencial y equipamientos o lugares de trabajo. Esto obedece a la necesidad de contener las áreas residenciales en una escala de actuación manejable por el sistema, en que se conserve el equilibrio entre áreas residenciales, productivas y dotacionales.

El resultado final es que la unidad de asentamiento resulta ser una entidad de población donde se pretende un cierto estilo de vida comunitario fundamentado en unos equipamientos y espacios de trabajo comunes. La población de cada unidad de asentamiento es de unos 12.000 habitan- tes; estas unidades se vuelven a agrupar para formar pequeñas ciudades de 50.000 a 70.000 que son las piezas elementales con las que se configuraría una metrópoli. (Hilberseimer 1944)

\section{- La supermanzana}

La supermanzana es la primera tentativa de Hilberseimer de articular el tejido urbano de la Mischbebauung basándose en una aplicación de las teorías de Ludwig Sierks; este ingeniero y urbanista alemán consideraba que con un área de unos $5 \mathrm{~km} 2$, malla de $1.600 \times 3.000 \mathrm{~m}$, sería económicamente rentable la sustitución de las vias perimetrales por autopistas con cuatro enlaces en trébol (Sierks 1929).

Hilberseimer estudia la aplicación de la supermanzana tanto a las áreas residenciales como a aquellos sectores destinados exclusivamente a uso comercial y administrativo. La supermanzana residencial (figura 34) consta de cuatro unidades de asentamiento con sus respectivos colegios y zonas verdes; las autopistas perimetrales permiten segregar el tráfico rodado del viario del tejido residencial que se dispone con una estructura en espina de pez y con vías en cul-de-sac.

La supermanzana de uso terciario se compone de cuatro grupos de edificios comerciales, conectados a la malla de autopistas y rodeados de un área verde. Volumétricamente los edificios tienen una configuración similar a los de la Hochhausstadt: con un zócalo de tres a cinco plantas sobre los que se alzan dos torres con planta en $\mathrm{H}$, herederas del tipo edificatorio del rascacielos de 1922 (Hilberseimer 1922) (figura 35).

En la supermanzana, Hilberseimer prosigue con el estudio de la edificación en altura para integrar el área comercial y de oficinas. Sobre la malla de Sierks se disponen ocho edificios en altura, con planta en
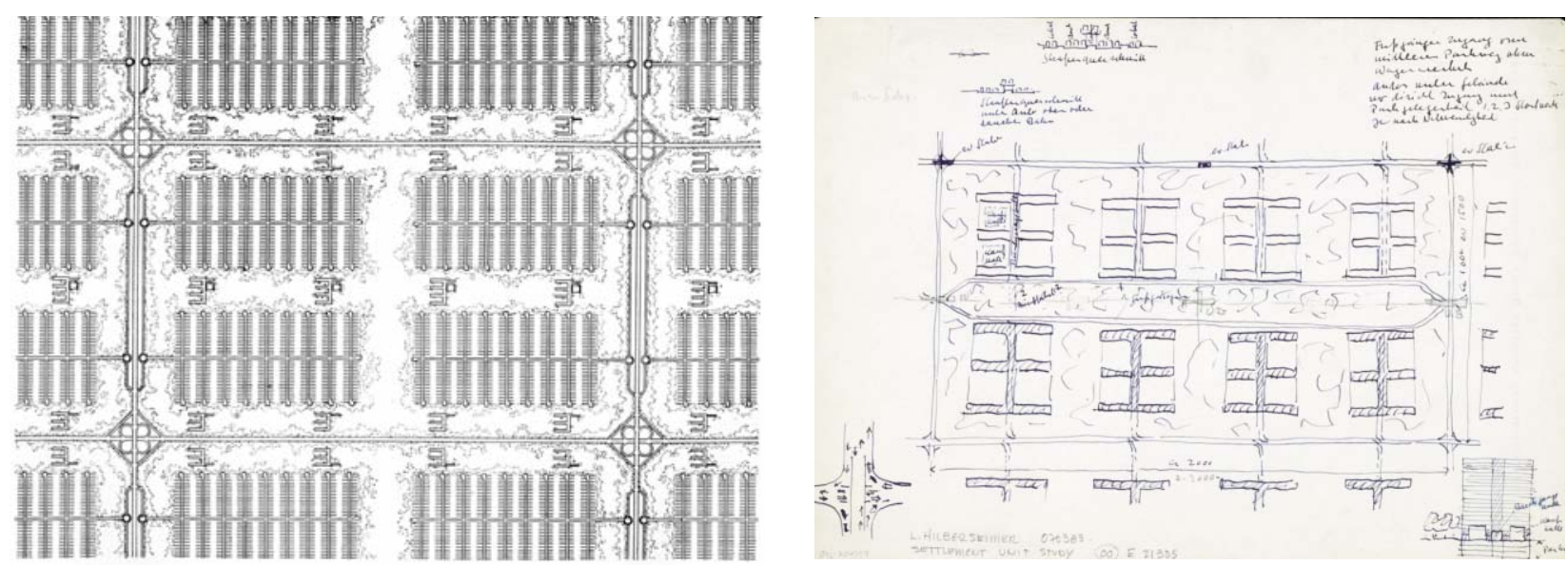


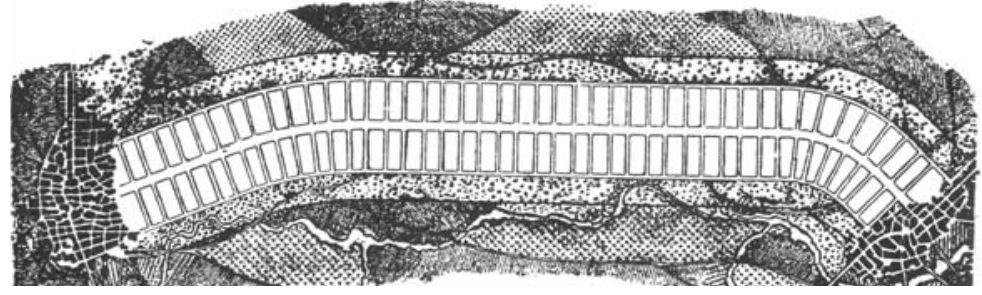

Derecha. Figura 36. La ciudad lineal de Arturo Soria (1894). (Hilberseimer 1944)

doble peine, en los que a un área de aparcamiento en sótano se incorpora el tráfico viario que atraviesa la edificación a nivel de rasante. Por vez primera se elimina el tránsito peatonal de la configuración del tejido urbano, confiando exclusivamente en el vehículo particular como medio de transporte prioritario dentro de la ciudad.

En la supermanzana la infraestructura viaria se convierte en una red circulatoria a la que se conectan directamente los tejidos residenciales y los edificios comerciales. Aunque Hilberseimer mantiene la base geométrica característica de los estudios precedentes, en la supermanzana la calle se ha independizado de la configuración tipológica de la edificación, perdiendo su cualidad urbana y transformándose en una gran infraestructura de escala supraurbana.

Pero Hilberseimer considera insatisfactoria la solución de la supermanzana, pues mantiene dos cuestiones que son las caras de un mismo problema asociado al sistema central o concéntrico. Por un lado la inadecuada integración en la trama de la red de metro y ferrocarril, pues el modelo de Sierks estaba pensado para el coche particular como medio de transporte preferente; por otro, se mantiene el problema de transporte ya que no disminuye el tráfico entre áreas residenciales y comercialesproductivas.

\section{- El sistema lineal}

El concepto que finalmente otorgará a los estudios de la Mischbebauung una estructura urbana y resolverá las relaciones entre áreas residenciales y productivas de la metrópoli es el linealismo, que Hilberseimer conoce gracias a los trabajos de la Ciudad Lineal de Arturo Soria presentados en la Deutsche Bauausstellung de Berlín en 1931.16 Hilberseimer tomará de Soria la correspondencia entre vialidad y estructura urbana que permite, además de la integración de las infraestructuras urbanas, el establecimiento de una jerarquía de tráfico peatonal-rodado. Es importante entender que el linealismo no es tanto una forma urbana como un modelo de generación de una estructura urbana, permaneciendo siempre como un sistema abierto a posibles ampliaciones. La obra de Arturo Soria sirve a comienzos de los años 30 como catalizador de las experiencias de Hilberseimer ofreciéndole un sistema de estructura urbana coherente con sus trabajos anteriores (figura 36).

De la unión de linealismo y Mischbebauung surge el nuevo modelo de la New City. Hilberseimer entiende que el sistema de organización lineal puede dar solución a los problemas que atenazan la metrópoli; si la Mischbebauung y los estudios de soleamiento resuelven el tema de vivienda, el linealismo afronta la circulación y el crecimiento de la metrópoli. Hilberseimer, al analizar las ventajas y desventajas del sistema lineal frente al concéntrico, escribe: "El sistema lineal, especialmente cuando se combina con establecimientos urbanos puntuales lo que incrementa su facilidad de uso y flexibilidad, es muy superior al sistema central para las necesidades actuales" (Hilberseimer 1944: 74).

\section{Los planes de Dessau y Berlín}

\section{Dessau}

El plan de Dessau es la primera aplicación práctica del modelo de la New City, en el que se introduce la configuración lineal en la organización urbana con la utilización de la unidad de asentamiento. Aunque no llegó a ser presentada, la propuesta para Dessau fue elaborada por Hilberseimer en colaboración con los estudiantes de la Bauhaus para el IV CIAM "La ciudad funcional" de 1933 (De Michelis 1986). Además de sede de la Bauhaus, Dessau era también objeto de proyecto para los alumnos de manera que este trabajo puede ser entendido como una síntesis de la experiencia didáctica de la Bauhaus (Droste 1993; Bruno 2008).

Hilberseimer inicia un proceso de análisis que parte de las condiciones preexistentes (objetivas) explicitando la topografia, los vientos predominantes, las relaciones entre los diferentes tejidos urbanos (residencial, terciario o industrial), su densidad edificatoria o la estructura de las infraestructuras viarias del conjunto; es decir se documentan todos aquellos parámetros susceptibles de configurar una información urbanística de calidad que permita orientar con la mayor objetividad posible las determinaciones de sus propuestas.

Dessau, que había sido la sede la Bauhaus, era en una ciudad industrial con graves problemas que se expresan grá- 
Figura 37. Estado inicial de Dessau (1932). (Hilberseimer 1944)

Figura 38. Propuesta para Dessau (1932). (Hilberseimer 1944)

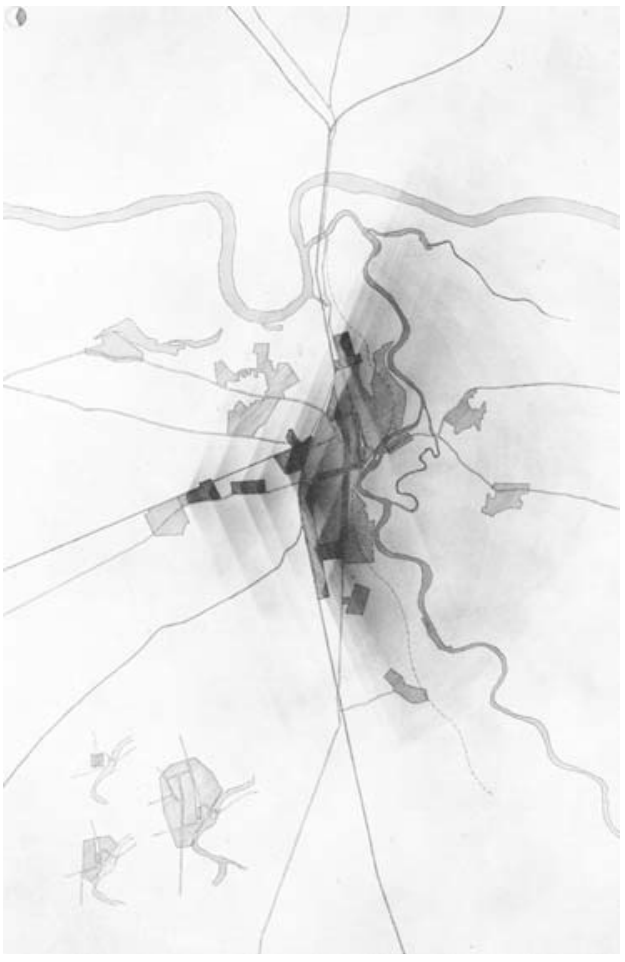

ficamente en este análisis (figura 37): las fábricas se sitúan en las proximidades de las líneas de ferrocarril, dirección nortesur y bifurcación hacia el este. Los vientos predominantes son de dirección oeste, por lo que la mayoria de las áreas residenciales sufren las consecuencias de la contaminación. El área residencial se localiza en terrenos que se inundan frecuentemente y se encuentra dividida por la carretera. Hilberseimer propone una solución expresada en un esquema gráfico con tres figuras que representan la situación actual y dos alternativas posibles. La primera es una solución parcial en la que se propone una redistribución de las áreas residenciales hacia el oeste, manteniendo e incluso ampliando el área industrial hacia el este. Ésta es una solución incompleta, pues toda ampliación del área residencial de la ciudad hacia el oeste implicaría un aumento de las distancias entre residencia y trabajo hasta hacer imposible una comunicación peatonal entre ellas. Pero el principio de acceder caminando al trabajo está ya incardinado en este nuevo modelo como medio de evitar el tráfico urbano y por eso se descarta esta reorganización parcial.

La opción definitiva (figura 38) proviene de la aplicación del principio de la unidad de asentamiento, combinada con un sistema de organización lineal. La ciudad se estructura en torno a las líneas de ferrocarril y de autopista que se integran en un corredor verde que separa las áreas de residencia e industria. Ésta se localiza hacia el este, a sotavento del área residencial. Hilberseimer organiza las áreas residenciales con doce unidades de asentamiento que agrupa en tres conjuntos de cuatro unidades. Las instituciones sociales y culturales, que se sitúan en los corredores verdes, se comparten cada dos unidades de asentamiento.

Aunque Dessau no es una metrópoli, en este plan podemos apreciar la fragmentación de la morfología urbana, pasando de una ciudad compacta a una difusa. Esto es, la idea de ciudad se difumina no sólo por el control establecido sobre la densidad, la introducción de las tipologías unifamiliares o los criterios de soleamiento, sino porque la inclusión del verde en el organismo segrega la ciudad en un conjunto de unidades morfológica y funcionalmente identificables. No es sólo que el sistema de organización central se haya perdido, sino que la propia idea de ciudad como organismo unitario se ha diluido en el entorno y se confia en la infraestructura viaria como elemento aglutinador de esta ciudad fragmentada. ${ }^{17}$

El plan de Dessau, por lo tanto, representa la aplicación de una idea global y unitaria, la New City; que se define como un modelo urbano difuso. De esta forma se configura una ciudad vaciada en su centro urbano, en la que la población se divide en unidades de asentamiento con sus equipamientos y servicios asociados que únicamente permanecen unidos por la infraestructura viaria (automóvil y ferrocarril) y por el espacio verde que penetra entre las unidades para albergar los equipamientos.

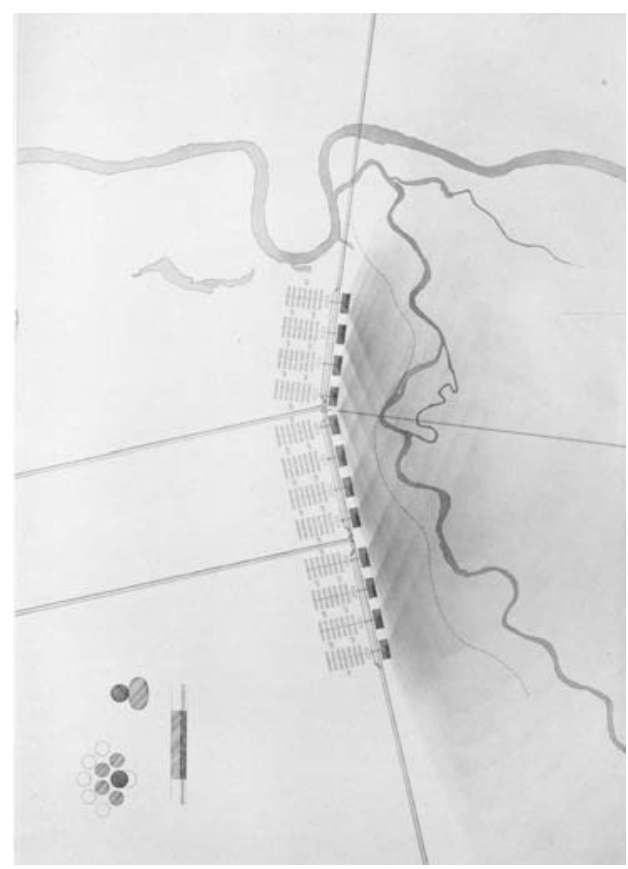


Figura 39. Plan Mächler para Berlin (1919). (Mächler, 1919)

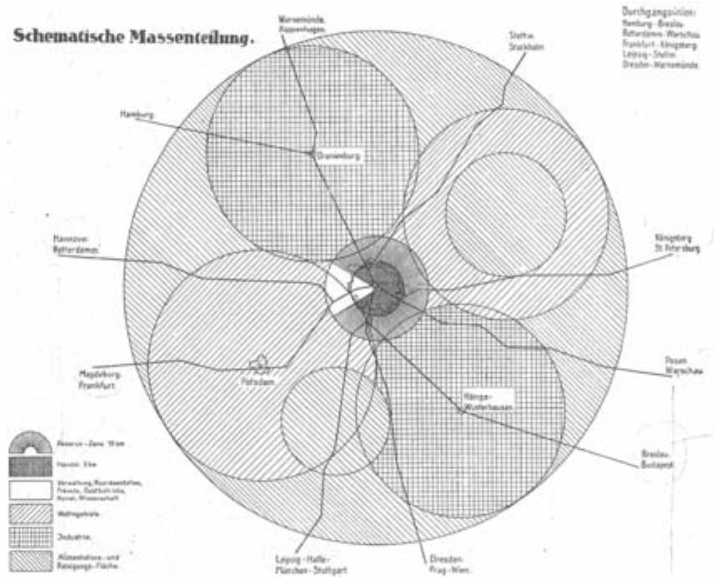

Hilberseimer profundiza en la idea de Bruno Taut de la disolución de las ciudades en su entorno gracias a los avances técnicos en comunicaciones que posibilitarán las necesidades de transporte de la población (Hilberseimer 1927).

También es ésta la primera vez que Hilberseimer propone la transformación y reurbanización integral de una ciudad real, perfilando un procedimiento que utilizará a mediados de la década de los 30 , para plantear la reconfiguración de una gran metrópoli como Berlín y que perfeccionará posteriormente en los Estados Unidos. ${ }^{18}$

Berlin

La propuesta para Dessau provoca una discusión entre Hilberseimer y sus amigos Martin Mächler19 y Alexander Schwab20 que dudaban de las posibilidades de adaptación del modelo de la New City a una metrópoli del tamaño de Berlín. (Hilberseimer 1963) El plan, Berlin descentralizado, es una tentativa inicial de aproximación a la metrópoli desde el modelo de la New City aplicado en una escala metropolitana y sobre una malla

Figura 40. Berlin descentralizado (1933-1935). (AIC)

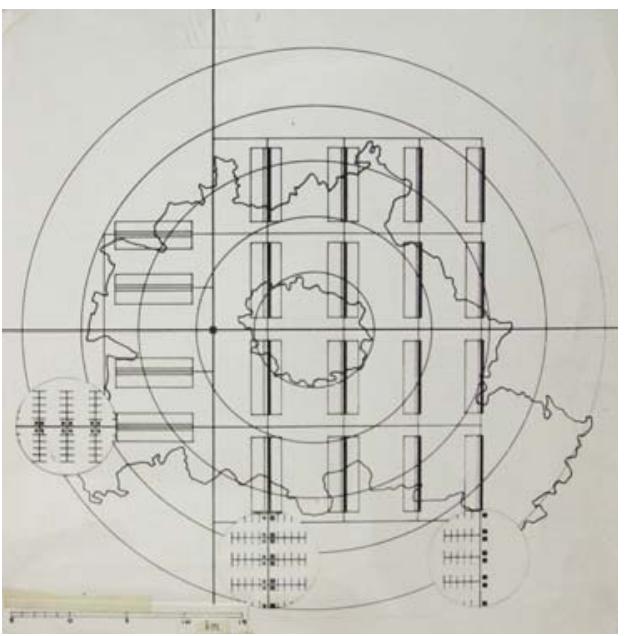

rectangular en la que se ubican 32 agregaciones de unidades de asentamiento con poblaciones de 125.000 habitantes cada una. Existen dos tipos de agregaciones, la de 125.000 habitantes con el área residencial a un único lado del área industrial y la de 250.000 habitantes con el área residencial en ambos lados. Con esa configuración Hilberseimer logra una ciudad difusa permeable al espacio verde para una población total de cuatro millones de habitantes y con una densidad poblacional de $200 \mathrm{hab} / \mathrm{Ha}$, aproximadamente la mitad que la densidad del Alt Berlin (Antiguo Berlin).

La configuración general de la metrópoli recuerda vagamente a la del plan de Mächler al que Hilberseimer se había adherido (figura 39). (Hilberseimer 1927b) Dos vías ortogonales, orientadas según los puntos cardinales, dividen el área de la ciudad en cuatro partes con su centro ligeramente desplazado hacia el oeste con respecto al Berlín real (figura 40). La disposición del área administrativa y comercial hacia el oeste recupera el sector administrativo del plan de Mächler que con centro en el ayuntamiento y con un ángulo de $60^{\circ}$ se abría también hacia el oeste de Berlín. 21

Sobre esta parte occidental, con las unidades orientadas este-oeste, se sitúan las áreas destinadas a los ministerios y administración pública así como al comercio y la banca. En el área oriental se ubican las unidades organizadas norte-sur con el comercio y la industria ligera en las dos primeras alineaciones de las agrupaciones y con la industria pesada, fuertemente contaminante sobre el extremo este de la ciudad (figura 41). ${ }^{22}$

La propuesta se completa con una perspectiva del área administrativa (figura 42) en la que se pueden observar los edificios en altura, con planta en $\mathrm{H}$ y 18 niveles, sobre las vías de comunicación que integran todo el proyecto.

A pesar de que la organización de las unidades de asentamiento y su agrupamiento es una aplicación del modelo de la New City, la concepción general todavía es la de una ciudad concéntrica y por lo tanto el Berlín descentralizado se convierte en un plan híbrido lineal-central. De ahí la crítica de Hilberseimer a este plan: "Es evidente la rigidez de este proyecto. Aun así, a pesar de sus defectos, y gracias a la unión horizontal de las zonas residenciales con las de trabajo mediante recorridos peatonales es mucho más avanzado que el primer plano de metrópoli con relación verti- 
Figura 41.

Disposición de la industria en el plan de Berlin descentralizado (19331935). (AIC)

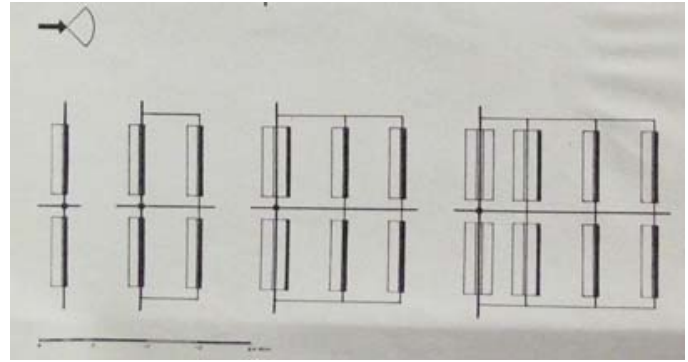

cal entre zona residencial y de trabajo. Constituye un decisivo paso adelante hacia el objetivo que deseamos obtener pero aún no una solución satisfactoria del problema". (Hilberseimer 1963: 49)

Esta organización híbrida surge como consecuencia de la adopción paulatina del linealismo pero también de la inicial adhesión de Hilberseimer al plan de Mächler y a que todavía no ha desarrollado estrategias de implantación del sistema lineal sobre una metrópoli. Habrá que esperar a su emigración a América en agosto de 1938 y sus trabajos sobre Chicago para encontrar una respuesta plenamente lineal a una escala metropolitana (Sumay 2014).

\section{Conclusiones}

Desde la autocrítica más radical y sincera $^{23}$ de sus modelos urbanos compactos, Wohnstadt o Hochhausstadt, Hilberseimer se propone adaptar la idea de metrópoli a las demandas de la sociedad, que es el verdadero objeto de su reflexión sobre la ciudad. Si la metrópoli es la representación de la sociedad capitalista, para Hilberseimer la vivienda es la expresión de la familia; la transformación de la forma de ambas, metrópoli y vivienda, es una consecuencia de los inevitables cambios en la forma de vida.

La investigación arquitectónica y urbanística de Hilberseimer implica la reducción elemental del problema metropolitano a una serie de cuestiones: la célula habitacional minima, la vivienda y la tipología residencial, el soleamiento y la densidad como parámetros modeladores, la circulación y la relación con el territorio. Cada una de estos temas son analizados por Hilberseimer en detalle pero sin perder la referencia a la naturaleza social, económica y territorial de la metrópoli. El desarrollo de una precisa metodología proyectual corre en paralelo a esta investigación, buscando enfrentarse a los problemas concretos pero manteniendo la continuidad del tránsito entre escalas: desde la célula habitacional mínima a la metrópoli territorial. La Mischbebauung, los estudios tipológicos de la vivienda y de soleamiento, la investigación del espacio doméstico en Die Wohnung unserer Zeit (La vivienda de nuestra época) o la modularidad y prefabricación de Das wachsende Haus (La vivienda que crece) configuran en su conjunto una respuesta global a la cuestión que plantea la metrópoli moderna.

El nuevo modelo que surge de estas investigaciones, la New City, es una metrópoli nueva, ya no caracterizada por la hiperdensidad y centralidad de los tejidos urbanos sino por su absoluto dominio del territorio, no es que la metrópoli haya desaparecido es que se ha disuelto en el paisaje.

Pero la elaboración de un nuevo modelo no es la meta final de los estudios de Hilberseimer, sino que su esencia reside en su capacidad de interaccionar con la realidad. Los planes para Dessau y Berlín suponen el primer paso de acercamiento a problemas concretos con diferentes escalas: una pequeña ciudad industrial y una gran metrópoli de ámbito continental. Ambas propuestas, aun siendo muy generales, representan las potencialidades de la aplicación de este modelo a la metrópoli moderna. El trabajo que Hilberseimer realizará en Chicago estará centrado en la implantación del modelo de la New City a una escala territorial y en el desarrollo de procedimientos de transformación urbana de la ciudad existente.

El camino que Hilberseimer recorre de la Hochhausstadt a la New City nos ha servido para apreciar la coherencia y el rigor de su metodología pero sobre todo para comprender de qué manera su investigación arquitectónica y urbanística está vinculada a la realidad social que tan bien conocía. Mies van der Rohe lo expresará así en
Perspectiva de una via administrativa en Berlin descentralizado (1933-1935). (AIC)

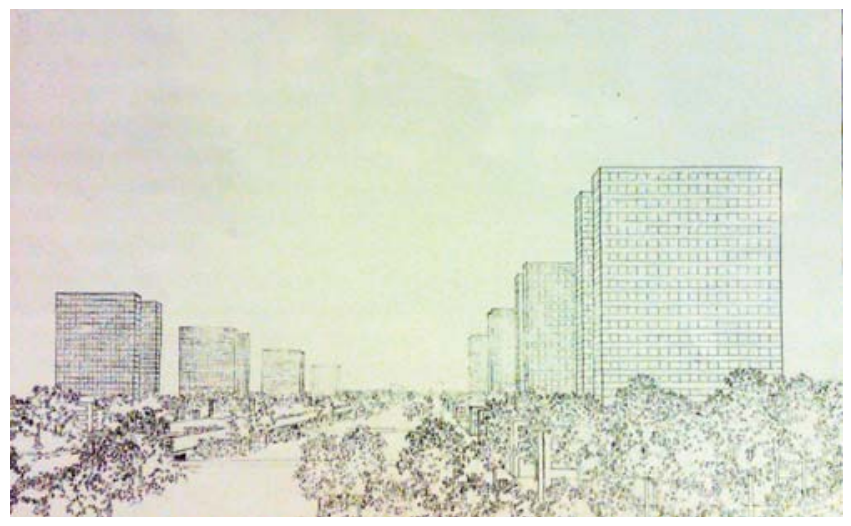


el prólogo a The New City: "(Hilberseimer) Sabe que las ciudades han de servir a la vida, que su valor y validez dependen de la vida y que han de planificarse para la vida. Interpreta las formas de la ciudad como expresión de los modelos de vida existentes, las considera inseparablemente ligadas a ellos y sabe que ambos están sometidos a transformaciones" (Mies van de Rohe, 1944:15).

\section{Notas}

1. "El rechazo de esta metrópoli fue también un desafio. (...) Ciertamente encontré una solución al problema del tráfico. ¡Pero a qué coste! El resultado fue un estéril y restrictivo paisaje de asfalto y hormigón." (Hilberseimer 1967b: 33)

2. Aunque la vinculación entre Hochhausstadt y Ville Contemporaine se fundamenta en la proximidad del viaje a París y su publicación (Mengin 1986), Hilberseimer reconoce que la idea de esta metrópoli vertical surge en una conversación informal con unos compañeros sobre la posibilidad de adaptar la idea de ciudad medieval a la metrópoli moderna uniendo espacio de trabajo y residencia en una misma edificación (Hilberseimer 1967b).

3. "Si bien no puede decirse que vivir en un pueblo en la década de 1930 fuera el paraíso, la difícil situación de pobreza en el ámbito urbano desarrollado se traducía en graves consecuencias, tanto materiales como psicológicas". (Weitz 2009: 198)

4. "Las comunidades son relativamente independientes y de dimensiones limitadas, lo que permite a la población atender sus propios intereses y llevar una autentica vida comunitaria, que la metrópoli moderna no permite". (Hilberseimer 1963: 84-85)

5. Hilberseimer adopta la equivalencia entre las tipologias, ambas provenientes de Estados Unidos, de la apartment house y la boarding house. La primera es un tipo de edificación colectiva con servicios comunes para permanencias medias y largas mientras que las boarding house es una forma de vivienda colectiva más próxima a un hotel con personal de servicio e importantes áreas comunes.

6. Aunque inicialmente Hilberseimer denomina a la urbanización mixta como Mischsiedlung vid. (Hilberseimer 1929) en escritos posteriores utilizará siempre el término Mischbebauung.

7. Este tejido presenta una densidad mínima próxima a $200 \mathrm{hab} / \mathrm{Ha}$.

8. Este conjunto de trabajos se desarrollan desde 1929 a 1932 y son publicados en Moderne Bauformen, Die Form, Bauhaus o Zentralblatt der Bauverwaltung. Las publicaciones más significativas son Großstadtische Kleinwohnungen (Las viviendas minimas en la metrópoli) (Hilberseimer, 1929), Flachbau und Stadtraum (La edificación baja y el espacio urbano) (Hilberseimer, 1931c) y Flachbau und Flachbautypen (La edificación baja y sus tipos) (Hilberseimer, 1932b).

9. La densidad media de Berlín es de $300 \mathrm{hab} / \mathrm{Ha}$, alcanzando en las partes más densamente pobladas los 383 hab/Ha (Hilberseimer 1931c).

10. Este esponjamiento de los tejidos residenciales, característico de la Mischbebauung, sería definido posteriormente por Hilberseimer como "the trend toward openess". Hilberseimer parte de la idea de la polis griega, como ciudad fortaleza compacta que domina un territorio, y que con la evolución histórica pasa por la ciudad medieval y renacentista en las que se acentúa el confinamiento, pero que a partir del siglo XIX se produce esa tendencia a la apertura presente también en la arquitectura y el urbanismo modernos, que buscan una penetración de la naturaleza logrando una mayor integración en el territorio. Cfr. (Hilberseimer 1960).

11. Esto estudios realizados en Alemania serán adaptados a la latitud de Chicago a partir de 1938 y refundidos en el cuerpo de su primera obra americana The New City.

12. Esta investigación de Hilberseimer debe ser entendida como la antitesis de la ponencia Flach-, Mittel-, oder Hochbau? (¿Edificación baja, media o alta?) de Walter Gropius en el III CIAM de Bruselas (1930) (Gropius, 1931).

13. La propia naturaleza creciente de la casa nos indica la adaptación de la arquitectura a la realidad financiera de sus propietarios. El Hauskern costaba unos 2500 marcos mientras que la casa completa se situaba en los 4500 marcos de tal manera que el sistema de crecimiento modulado permite dimensionar la vivienda a las necesidades y capacidades económicas de sus habitantes. Vid. (Wagner 1932).

14. La datación de 1927 que consta en el AIC, entendemos que no se corresponde con el análisis morfológico y contextual dentro de la obra de Hilberseimer: en 1927, aún no habia completado el estudio de la Mischbebauung, ni establecido todavia la vivienda unifamiliar como forma residencial prioritaria, tampoco había adoptado el sistema lineal, elementos constitutivos en la configuración del sistema de planificación basado en las unidades de asentamiento. Sería más apropiado situarlo entre 1932 como eslabón entre las experiencias de la Mischbebauung y el plano de Dessau que es la primera aplicación plena del modelo.

15. Según Reginald Malcolmson en ningún caso superaria la milla de distancia, cfr. (Malcolmson 1968).

16. "En 1882 un escritor español, Soria y Mata, propuso la Ciudad Lineal que hoy en dia ha suscitado un intenso interés bajo el nombre de 'Ribbon city'. En 1931 en la decimotercera exposición internacional de urbanismo de Berlín las ideas de Soria y Mata tuvieron gran difusión gracias a la presentación de una edición conmemorativa de La Ciudad Lineal". (Hilberseimer 1940:100)

17. "Aunque separada por estos parques todas las unidades de los tres grupos que constituyen el asentamiento, forman en su conjunto un organismo urbano". (Hilberseimer 1944: 134)

18. El método de replanificación introducido por Hilberseimer de una manera genérica en el plano de Dessau, será aplicado durante el exilio americano, a partir de 1938, a un buen número de grandes ciudades norteamericanas como Chicago, Nueva York o Montreal, a ciudades medianas como St Paul, Elkhorn o Rockford, pero también se estudiará su aplicación parcial a áreas urbanas de la metrópoli como son los proyectos en Chicago para el North Side, Marquette Park o Hyde Park, donde las estrategias de reurbanización son estudiadas cuidadosamente con una clara secuenciación de las fases. Cfr. (Llobet 2007; Scotti 2008).

19. Martin Mächler publica en 1919 Denkschrift betreffend eine Ergänzung des Gesetzentwurfes zur Bildung eines Stadtkreises Gross-Berlin Informe relativo a una enmienda al proyecto de ley para configurar el distrito urbano del Gran Berlin) donde sintetiza su propuesta para el Groß-Berlin. El plan de Mächler es la primera tentativa de estructurar de una manera global y comprehensiva, con una representación sintética de la metrópoli y a una escala adecuada, la ciudad de Berlín gracias a la organización de la misma por medio de la separación de funciones en áreas independientes y la proposición de un 
sistema ferroviario que conecte dichas áreas. Hilberseimer y otros arquitectos de Der Ring toman este plan como marco sustancial al que referir sus propuestas urbanas. Cfr. (Hilberseimer 1927b)

20. Alexander Schwab (1887-1943) fue un sociólogo, periodista y político comunista alemán. Miembro del KPD (Partido Comunista de Alemania) y fundador del KAPD (Partido de los Trabajadores de Alemania escisión del KPD durante la República de Weimar), Schwab fue un destacado activista político y como periodista trabajó en la revista de la Werkbund, Die Form.

21. Ambos planes son coherentes con las formas urbanas de crecimiento de Berlin y su expansión hacia el oeste con la configuración del núcleo administrativo del Reich en un eje nortesur paralelo a la Friedrichstraße.

22. El viento predominante de Berlín proviene del oeste, del mar del Norte y Brandenburgo por lo que la situación de la industria pesada se ubica en el este, a sotavento. (Weitz 2009)

23. "Más una necrópolis que una metrópoli, inhumana en todos los aspectos" (Hilberseimer, 1967b: 41)

\section{Bibliografia}

Fuentes primarias de Hilberseimer:

L. K. Hilberseimer Archives. The Art Institute of Chicago (AIC).

Hilberseimer, Ludwig-Karl. 1922. Das Hochhaus. Das Kunstblatt, 6: 525-531.

Hilberseimer, Ludwig-Karl. 1924. Nur Einbau. Das Bauwelt-Haus: 63-64

Hilberseimer, Ludwig-Karl. 1925. Grosstadtbauten. En Grosstadtbauten et altre escritti di arte e di architettura. Napoles: CLEAN. 2010.

Hilberseimer, Ludwig-Karl. 1927 Groszstadtarchitektur. Stuttgart: Julius Hoffmann. Ed. española: La arquitectura de la gran ciudad. 1999. Barcelona: Gustavo Gili.

Hilberseimer, Ludwig-Karl. 1927. Struktiver Städtebau. Das Kunstblatt, 11: 267-271.

Hilberseimer, Ludwig-Karl. 1928. Wohnung und Familie. Mecanoscrito inédito. AIC S 8/2-B2F16.

Hilberseimer, Ludwig-Karl.1929. Großstadtische Kleinwohnungen. Zentralblatt der Bauverwaltung, 32: 509-514.

Hilberseimer, Ludwig-Karl. 1931. Die Kleinstwohnung im Treppenlosenhaus. Bauhaus, 1: 1-2.

Hilberseimer, Ludwig-Karl.1931. Die Wohnung unserer Zeit. Die Form, 6: 249-270.

Hilberseimer, Ludwig-Karl. 1931. Flachbau und Stadtraum. Zentralblatt der Bauverwaltung vereinigt mit Zeitschrift für Bauwesen, 53/54: 773-777Hilberseimer, Hilberseimer, LudwigKarl. 1932. Das wachsende Haus. En: Wagner, Martin, Das wachsende Haus. Berlin: Deutsches Verlagshaus Bong.72-75.

Hilberseimer, Ludwig-Karl. 1932. Flachbau und Flachbautypen. Moderne Bauformen, 31: 471478

Hilberseimer, Ludwig-Karl. 1935. Raumdurchsonnung. Moderne Bauformen, 34: 29-36.

Hilberseimer, Ludwig-Karl. 1936. Raumdurchsonnung und Siedlungsdichtigkeit. Moderne Bauformen, 35: 69-76.

Hilberseimer, Ludwig-Karl. 1940. The literature of city planning. Architectural Forum, 73: 100101 .

Ludwig-Karl. 1944. The New City. Principles of Planning. Chicago: Paul Theobald.
Hilberseimer, Ludwig-Karl. 1949. The New Regional Pattern. Industries and Gardens Workshops and Farms. Chicago: Paul Theobald.

Hilberseimer, Ludwig-Karl. 1955. The Nature of Cities. Chicago: Paul Theobald.

Hilberseimer, Ludwig-Karl. c. 1960. City architecture: The trend toward openness. En: Pommer, Richard, Spaeth, David y Harrington, Kevin. 1988. In the shadow of Mies. Ludwig Hilberseimer. Architect, Educator and Urban Planner. New York: Rizzoli International Publications.

Hilberseimer, Ludwig-Karl. 1963. Entfaltung einer Planungsidee. Berlin: Ullstein.

Hilberseimer, Ludwig-Karl. 1967. Berliner Architektur der 20er Jahre. Mainz: Florian Kupferberg.

Hilberseimer, Ludwig-Karl. 1967. Density and traffic. En: Sharp, Dennis, Planning and architecture. Londres: Barry \& Rockliff. 31-35.

Bibliografia complementaria

Aureli, Pier-Vittorio. 2011. Architecture for Barbarians: Ludwig Hilberseimer and the Rise of the Generic City. AA Files, 63: 3-18.

Behrens, Peter, y De Fries, Heinrich.1918. Vom sparsamen Bauen. Berlin: Bauen.

Bruno, Francesco. 2008. Ludwig Hilberseimer. La construzione di unídea di cittá. Il periodo tedesco. Milán: Libraccio. 2008.

Cacciari, Massimo. 1972. Dialéctica de lo negativo en las épocas de la metrópoli. En Tafuri, Manfredo, Cacciari, Massimo y Dal Co, Francesco, De la vanguardia a la metropoli. Crítica radical de la arquitectura. Barcelona: Gustavo Gili. 79-152.

De Michelis, Marco.1986. Ritratto di un architetto come giovane artista. Rassegna, 27: 6-25.

Droste, Magdalena.1993. Bauhaus. Berlin: Bauhaus-Archiv Taschen.

Gropius, Walter. 1931. Flach-, Mittel-, oder Hochbau? (Conferencia en el III CIAM celebrado en Bruselas del 27 al 29 de noviembre de 1930). Publicado en Das neue Frankfurt, 2: 22-34

Howard, Ebenezer. 1898. To-Morrow: a peaceful path to real reform. (Consultado en la edición de 2003, London: Routledge).

Llobet, Xavier. 2007. Hilberseimer y Mies. La metrópoli como ciudad jardin. Barcelona: Fundación Caja de Arquitectos.

Kropotkin, Piotr.1898. Fields, Factories and Workshops. (Consultado en la edición de 1993, New Jersey: Transaction Publishers).

Mächler, Martin. 1919. Denkschrift betreffend eine Ergänzung des Gesetzentwurfes zur Bildung eines Stadtkreises Gross-Berlin. Der Städtebau.

Malcolmson, Reginald. 1968. La obra de Ludwig Hilberseimer. Elementos de la nueva ciudad. Hogar y arquitectura, 76: 52-56.

Mengin, Christine. 1986. Regesto delle opere e de progetti 1885/1938. Rassegna, 27: 78-88.

Mies van der Rohe, Ludwig. 1944. Introduction. En: Hilberseimer, Ludwig-Karl, The new city: Principles of planning. Chicago: Paul Theobald.

Pommer, Richard, Spaeth, David y Harrington, Kevin. 1988. In the shadow of Mies. Ludwig Hilberseimer. Architect, Educator and Urban Planner. New York: Rizzoli International Publications.

Scotti, Francesca. 2008. Ludwig Hilberseimer. Lo sviluppo di un ¿idea di città. Il periodo americano. Milán: Libraccio.

Sierks, Ludwig. 1929. Grundriss der sicheren rei- 
chen ruhigen Stadt. Dresden: Kaden \& Co.

Simmel, Alice. 1929. Die neue Küche. Die Form, 4: 289-291.

Simmel, Georg. 1903. Die Grosstädte und das Geistesleben. En: Simmel, Georg, El individuo y la libertad. Barcelona: Ediciones Peninsula, 2001: 375-398.

Sumay, José-Antonio. 2014. Hilberseimer. El urbanismo de la gran ciudad. Tesis doctoral. A Coruña: Universidade da Coruña.

Soria Mata, Arturo. La Ciudad Lineal, antecedentes y datos varios acerca de su construcción. Madrid: Imp. Sucesores de Rivadeneyra, 1894.

Tafuri, Manfredo. 1980. La esfera y el laberinto. Vanguardias y arquitectura de Piranesi a los años setenta. Barcelona: Gustavo Gili.

Tafuri, Manfredo.1972. Para una critica de la ideologia arquitectónica. En: Tafuri, Manfredo, Cacciari, Massimo y Dal Co, Francesco, De la vanguardia a la metropoli. . Crítica radical de la arquitectur. Barcelona: Gustavo Gili. 13-69.

Weitz, Eric D. 2009. La Alemania de Weimar. Presagio y tragedia. Madrid: Turner Publicaciones.

Fecha de entrega del articulo: 14/04/ 15

Fecha de aceptación:

$15 / 06 / 15$

Articulo sometido a revisión por dos revisores independientes por el método doble ciego. 